EUROPEAN CENTRAL BANK WORKING PAPER SERIES

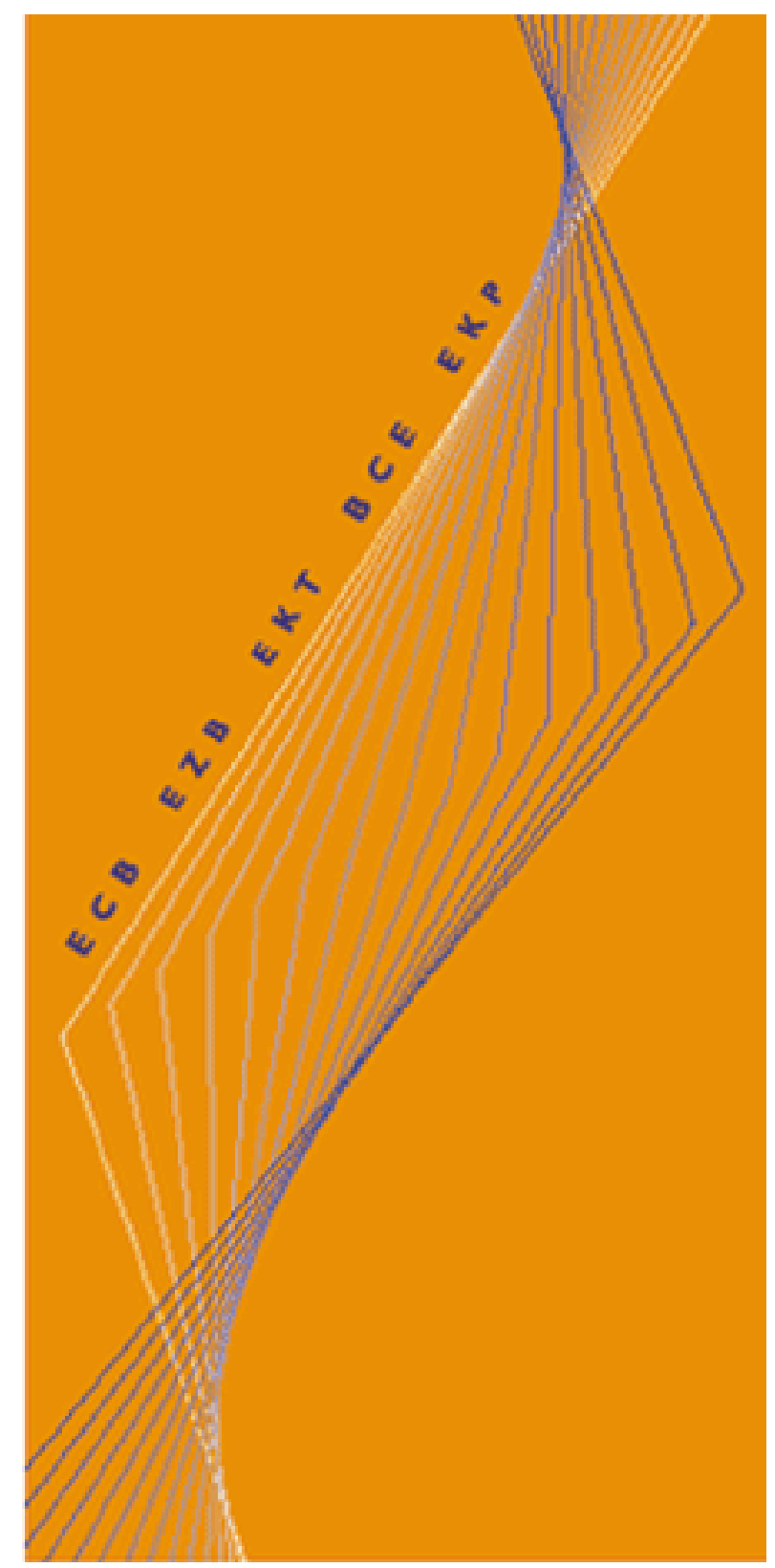

WORKING PAPER NO. I 52

SHORT-TERM MONITORING OF FISCAL POLICY DISCIPLINE

BY GONZALO CAMBA-MENDEZ AND ANA LAMO

June 2002 


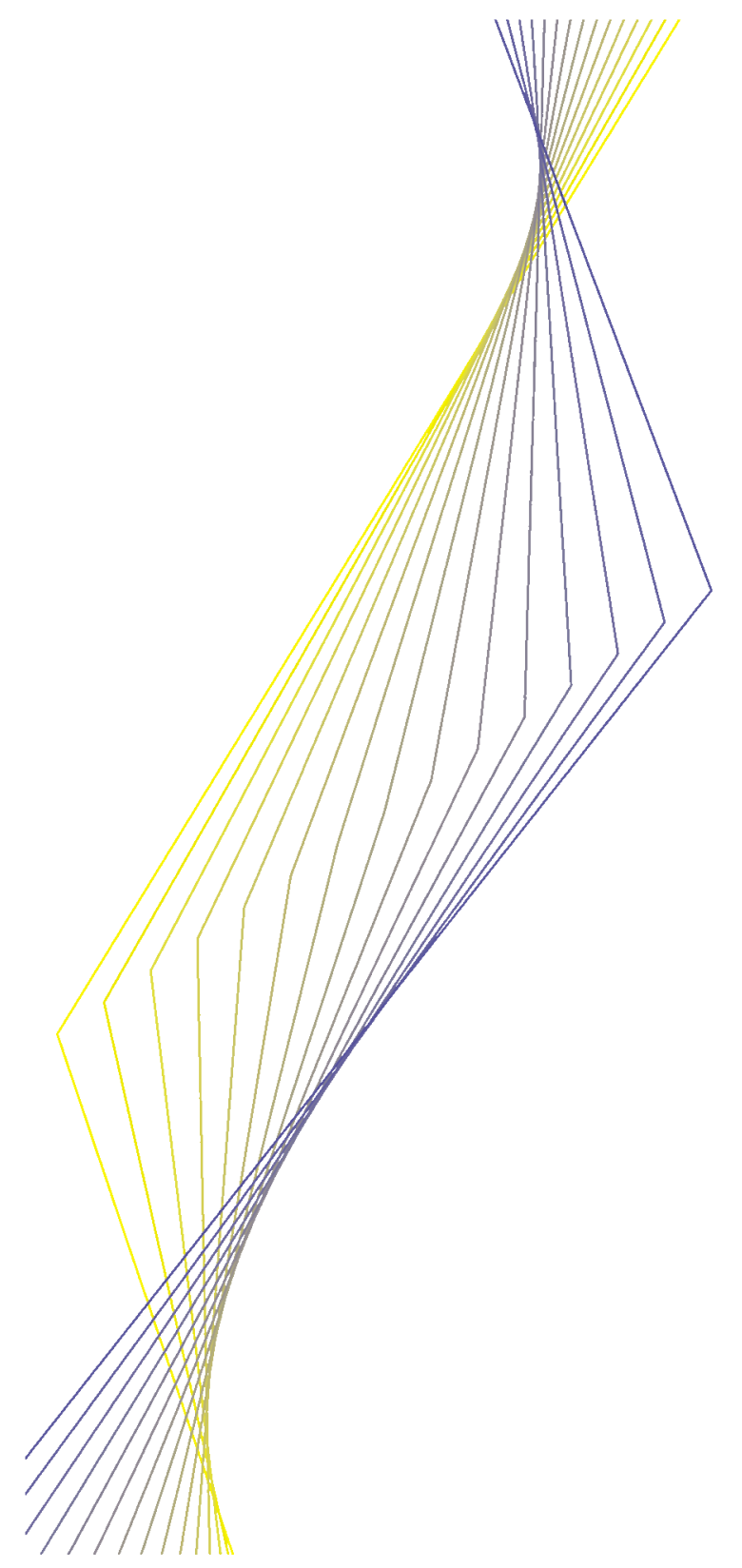

WORKING PAPER NO. I 52

SHORT-TERM MONITORING OF FISCAL POLICY DISCIPLINE

BY GONZALO CAMBA-MENDEZ AND ANA LAMO*

\section{June 2002}


(C) European Central Bank, 2002

\begin{tabular}{|c|c|}
\hline \multirow[t]{2}{*}{ Address } & Kaiserstrasse 29 \\
\hline & D-603 I I Frankfurt am Main \\
\hline & Germany \\
\hline \multirow[t]{3}{*}{ Postal address } & Postfach 160319 \\
\hline & D-60066 Frankfurt am Main \\
\hline & Germany \\
\hline Telephone & +496913440 \\
\hline Internet & http://www.ecb.int \\
\hline Fax & +496913446000 \\
\hline Telex & 4 I I I44 ecb d \\
\hline
\end{tabular}

Reproduction for educational and non-commercial purposes is permitted provided that the source is acknowledged.

The views expressed in this paper are those of the authors and do not necessarily reflect those of the European Central Bank.

ISSN $156 \mid-0810$ 


\section{Contents}

$\begin{array}{ll}\text { Abstract } & 4\end{array}$

$\begin{array}{ll}\text { Non-technical summary } & 5\end{array}$

$\begin{array}{llr}\text { I Introduction } & 7\end{array}$

2 The structural budget balance ratio 9

2.I The problem of estimating structural budget balances $\quad 10$

2.2 The problem of quarterly data availability II

3 An UC Model of the budget balance ratio $\quad 12$

3.I Building quarterly series for budget balance ratios $\quad 14$

$4 \quad$ Empirical results $\quad 16$

4.I The data 16

$\begin{array}{lll}4.2 & \text { Country results } & 16\end{array}$

$5 \quad$ Summary and conclusions $\quad 20$

A Appendix $\quad 21$

A.I State space representation: quarterly frequency 21

$\begin{array}{lll}\text { A.2 State space representation: annual frequency } & 21\end{array}$

$\begin{array}{lll}\text { A.3 Kalman filtering with partial updating } & 21\end{array}$

$\begin{array}{ll}\text { A4 The fixed interval smoothing algorithm } & 22\end{array}$

$\begin{array}{ll}\text { References } & 23\end{array}$

$\begin{array}{ll}\text { Tables \& Figures } & 25\end{array}$

European Central Bank working paper series $\quad 35$ 


\begin{abstract}
Under the Maastricht Treaty and the Stability and Growth Pact (SGP) European Union (EU) Member States commit themselves to avoid excessive deficits over $3 \%$ of GDP and to pursue the medium-term objective of budgetary positions close to balance or in surplus. The SGP provides also regulation for the surveillance of budgetary positions. An analysis of associated tools is the focus of this paper. In particular, it addresses two open issues in the empirical public finance literature which are crucial for monitoring fiscal policy discipline in the EU. First, the estimation of the structural component of the fiscal balance ratio. Second, the computation, when only annual fiscal data is available, of quarterly budget balance ratios, using relevant information from quarterly measured macroeconomic series. An econometric model that addresses both issues is presented and estimated. Additionally, this modelling framework allows us to answer questions such as: what is the safety margin that will prevent a particular country from reaching with certain probability a budget deficit that breaches the $3 \%$ upper bound?
\end{abstract}

Keywords: Structural Deficit Ratio, State Space Modelling, Interpolation.

JEL: C32, E60 and H62. 


\section{Non-Technical Summary}

Over the last years several OECD countries have devoted large efforts to put their fiscal situation under control. This has translated in the introduction of various budget restrictions as one of the pillars underlying their fiscal policies. The Treaty of the European Union signed in Maastricht in February 1992 stated in Article 104 that member states shall avoid excessive government deficits. The protocol on the Excessive Deficit Procedure annexed to the Treaty specified the reference values of $3 \%$ for the ratio of government deficit to GDP at market prices, and $60 \%$ for the ratio of government debt to GDP at market prices. Member states are fully responsible for their national fiscal policies which should be conducted subject to the provisions of the Treaty. On the 17th June 1997 the European Council passed a resolution on a Stability and Growth Pact (SGP) which refines and develops the fiscal provision of the Maastricht Treaty.

Under the SGP EU members commit themselves to respect the medium-term budgetary objective of positions 'close to balance or in surplus' which must be set out in their annual stability programmes. This will allow member states to deal with normal cyclical fluctuations while respecting the Treaty obligation to avoid excessive deficits over 3\% of GDP. A precise definition of the underlying figure associated with such a close-to-balance position, which might be different across countries, is not specified in the SGP.

Therefore the SGP implicitly acknowledges the standard decomposition of budget balances into (at least) two components: (i) a component arising exclusively from discretionary policy measures taken by the fiscal authority, which in turn determines the medium-term component of the budget balances, usually known as the structural or cyclically adjusted budget balance, and (ii) a cyclical component arising from real GDP fluctuations.

In this vein, the common practice when implementing fiscal policy monitoring is to look at annual budget figures corrected of cyclical fluctuations i.e. the structural component. The reliability of this measure as an indicator for effective short-term monitoring of the fiscal stance is often plagued by two types of problems. First, the difficulty in constructing such a measure, i.e. identifying separately the short-term (cyclical) and the medium-term (structural or cyclically adjusted) components. These components are not observable and there is no consensus in the literature about the most appropriate method to identify them. Second, fiscal variables are available only at an annual frequency for most countries, which makes short-term monitoring impracticable. These two problems are addressed in this paper.

The aim of this paper is to develop a valid modelling framework for the short-term monitoring of fiscal stance. It does so by setting up an Unobserved Component (UC) model with an unbalanced dataset of quarterly and annual series. The model provides a valid 
framework to build an interpolated quarterly series of the deficit ratio and to identify its different components that add up to the observed series. These components are: i) a structural budget balance ratio, ii) a cyclical budget balance ratio arising from fluctuations in real GDP, iii) a cyclical component arising from changes in inflation, and iv) a measurement error component.

The decomposition obtained from our statistical approach is a useful complement to existing measures for two main reasons. First, it easily derives uncertainty bounds around the estimated structural (and cyclical) budget balance ratios, which is an additional important element in a complete assessment of the fiscal stance. Second, our approach can easily incorporate the effect of additional determinants of the fiscal stance in the overall assessment, like inflation, proxies to population ageing, interest rates, etc. We extend the model to incorporate inflation which enables us to identify cyclical fluctuations arising from price dynamics. This also serves to improve the short to medium-term forecast of the budget balance ratio by incorporating available information on price developments.

Interestingly, our analysis yields objective, well-defined and still easily computable figures for the structural budget balance ratio, that would have to be targeted to fulfil the Maastricht criteria in the future, with any given probability. 


\section{Introduction}

Over the last years several OECD countries have devoted large efforts to put their fiscal situation under control. This has translated in the introduction of various budget restrictions as one of the pillars underlying their fiscal policies. Alesina and Perotti (1996) suggest that the adoption of laws that establish limits on the deficits, budget balance laws, may contribute to enforce fiscal discipline.

Over the past twenty years in the US there have been numerous discussions on the amendment of the constitution to mandate a balanced budget: the Balanced Budget Amendment (BBA). In 1995 a BBA failed to be approved in the Senate by just one vote. Some argued that had the BBA enforced no federal borrowing from the Social Security Trust, it would have been approved. In 2002 a new BBA resolution is being introduced in Congress.

In the European Union budget laws have been put in place. The Treaty of the European Union signed in Maastricht in February 1992 stated in Article 104 that member states shall avoid excessive government deficits. The protocol on the Excessive Deficit Procedure annexed to the Treaty specified the reference values of $3 \%$ for the ratio of government deficit to GDP at market prices, and $60 \%$ for the ratio of government debt to GDP at market prices. Member states are fully responsible for their national fiscal policies which should be conducted subject to the provisions of the Treaty. On the 17th June 1997 the European Council passed a resolution on a Stability and Growth Pact (SGP) which refines and develops the fiscal provision of the Maastricht Treaty. The SGP consists of this Council Resolution and two Council Regulations, one on the strengthening of the surveillance of budgetary positions and the surveillance and coordination of economic policies and another on speeding up and clarifying the implementation of the excessive deficit procedure ${ }^{1}$. Under the SGP EU members commit themselves to respect the medium-term budgetary objective of positions 'close to balance or in surplus' which must be set out in their annual stability programmes. This will allow member states to deal with normal cyclical fluctuations while respecting the Treaty obligation to avoid excessive deficits over $3 \%$ of GDP. A precise definition of the underlying figure associated with such a close-to-balance position, which might be different across countries, is not specified in the SGP. A fiscal deficit in excess of $3 \%$ will only be allowed if 'exceptional conditions' persist. The SGP defines 'exceptional conditions' in terms of annual falls in real GDP ${ }^{2}$.

\footnotetext{
${ }^{1}$ Council Regulations (EC) Nos 1467/97 and 1466/97 of 7 July 1997.

${ }^{2}$ Falls of at least $2 \%$ are understood as exceptional conditions. Falls in annual real GDP in between $0.75 \%$ and $2 \%$ could be regarded as 'exceptional conditions' only accompanied by further evidence. Falls smaller than $0.75 \%$ will never be regarded as 'exceptional conditions'. The SGP specifies also sanctions in the event of persistent deficit ratios in excess of $3 \%$.
} 
Therefore the SGP implicitly acknowledges the standard decomposition of budget balances into (at least) two components: (i) a component arising exclusively from discretionary policy measures taken by the fiscal authority, which in turn determines the medium-term component of the budget balances, usually known as the structural or cyclically adjusted budget balance, and (ii) a cyclical component arising from real GDP fluctuations.

In this vein, the common practice when implementing fiscal policy monitoring is to look at annual budget figures corrected of cyclical fluctuations, i.e. the structural component. The reliability of this measure as an indicator for effective short-term monitoring of the fiscal stance is often plagued by two types of problems. First, the difficulty in constructing such a measure, i.e. identifying separately the short-term (cyclical) and the medium-term (structural or cyclically adjusted) components. These components are not observable and there is no consensus in the literature about the most appropriate method to identify them. Second, fiscal variables are available only at an annual frequency for most countries, which makes short-term monitoring impracticable. These two problems are addressed in this paper.

Recently, numerous research has been conducted with the aim to study how best to put into practice the guidelines set out by the SGP to strengthen the surveillance of budgetary positions (see Buti, Franco, and Ongena (1998), Dalsgaard and de Serres (1999) and European-Commission (2000)). The work presented in this paper attempts to contribute to this literature.

The aim of this paper is to develop a valid modelling framework for the short-term monitoring of fiscal stance. It does so by setting up an Unobserved Component (UC) model with an unbalanced dataset of quarterly and annual series. The model provides a valid framework to build an interpolated quarterly series of the deficit ratio and to identify its different components that add up to the observed series. These components are: i) a structural budget balance ratio, ii) a cyclical budget balance ratio arising from fluctuations in real GDP, iii) a cyclical component arising from changes in inflation, and iv) a measurement error component. The estimated model allows us to compute, for example, the safety margins which should be targeted for the structural budget balance ratio to prevent, in the case of adverse economic conditions, breaching the $3 \%$ reference value of the Maastricht Treaty. Empirical results are provided for Germany and Italy.

The rest of the paper is organized as follows. Section 2 briefly reviews how to estimate the budget balance structural component and the availability of quarterly fiscal data. Section 3 lays out the modelling framework for the short-term monitoring of fiscal discipline, in particular our assumptions about the trend and cycle components of GDP and budget balance-to-GDP ratio. This section also describes the method developed to interpolate ratios in the state-space setting and the steps taken for estimating parameters and producing 
quarterly budget balance ratio figures while providing a decomposition of these quarterly figure into its components. Section 4 shows the results of applying to Germany and Italy the methods described in the previous sections and section 5 concludes.

\section{The Structural Budget Balance Ratio}

The structural budget balance ratio is used as the indicator to monitor the compliance with the medium-term fiscal discipline in EMU. The idea behind this is the standard decomposition of the budget balance into a structural and a cyclical component. This standard decomposition of the budget balance can also be seen as a fiscal policy rule analogously to a monetary policy rule, see Taylor (2000). We follow Taylor (2000) but rather than having two components we extend his definition to include a third component. We assume that a fiscal policy rule takes the following form:

$$
d_{t}=\mu_{t}+\alpha_{1} \psi_{t}+\lambda z_{t}
$$

where $d_{t}$ is the actual budget balance ratio, $\mu_{t}$ is the structural budget balance, $\psi_{t}$ is the deviation of the GDP from its potential value, i.e. the output gap and therefore $\alpha_{1} \psi_{t}$ is the cyclical component of the actual budget balance ratio arising from GDP fluctuation, and $\boldsymbol{z}_{t}$ represents a set of exogenous economic factors which are not under the direct control of fiscal authorities but have an impact on the budgetary position. The structural component is strictly related to discretionary fiscal policy measures. This includes countercyclical measures as well as measures which are driven primarily by political factors. By this it is meant those which are in line with promises made by a political party during the elections, and subsequently in line with promises raised during the time spent by that party in government. The cyclical component represents the impact of automatic stabilizers on the budget balance. Automatic stabilization is defined as the impact that fluctuations in economic activity have on the budget in the absence of any government action ${ }^{3}$. Automatic stabilizers refer mainly to the elasticity of transfers and taxes to fluctuations in economic activity and to the progressivity of the tax and transfer system. The exogenous economic factors include variables such as the inflation rate, which is the one we include in our estimated model and allows to account for cyclical fluctuations resulting from changes in the level of inflation and their impact on, for example, tax collection. Other interesting variables to introduce as exogenous in our model could be proxies of the population age evolution to account for the fiscal cost of ageing that many Member States start to face. Changes in interest rates which have an impact on the cost of financing the public debt could be as well taken into

\footnotetext{
${ }^{3}$ See ECB (2002) for a review on the operation of automatic fiscal stabilisers in the euro area.
} 
consideration ${ }^{4}$.

The reliability of the structural budget balance as an indicator for effective short-term monitoring of the fiscal stance is often plagued by two types of problems. First, the difficulty in constructing such a measure, i.e. identifying separately the short-term (cyclical) and the medium-term (structural or cyclically adjusted) components. Second, fiscal variables are available only at an annual frequency for most countries, and this makes short term monitoring impracticable.

\subsection{The Problem of Estimating Structural Budget Balances}

The structural budget balance is not observable and there is no consensus in the literature about the most appropriate method to identify it. Two leading empirical approaches have been taken in the literature to estimate the structural fiscal balance ${ }^{5}$. We will label these approaches as two-step and direct respectively.

The two-step approach. This approach focuses primarily on fluctuations of the budget balance ratio which are induced by fluctuations in output at business-cycle frequencies. As the first step a measure of the output gap is computed as a function of deviations of observed from potential output, the latter is typically calculated through the Hodrick-Prescott filter or a production function. Second, the cyclical component of budget balance is obtained by applying to the output gap the so-called fiscal elasticities, which measure the effects of output movements on the fiscal budget balance. The structural component is computed as the difference between observed and cyclical budget balance. The two-step approach is the most widely used by international institutions (IMF, European Commission and OECD among others) and also by national agencies for official estimates of the cyclically-adjusted budget balance. Blanchard (1993) suggested an alternative approach that rather than using potential output makes use of changes in the unemployment rate. An advantage of the two-step approach is its relative simplicity and the fact that it yields a cyclically-adjusted balance which has a straightforward interpretation. A drawback of this approach is that it is subject to uncertainty coming from two sources: the measurement of potential output and the estimation of the fiscal elasticities. The fact that the two estimations are combined sequentially makes the error bounds of the final structural budget balance difficult to com-

\footnotetext{
${ }^{4}$ To do this properly would require at least two types of information: the maturity structure of the different debt instruments and the typical interest rate for each instrument and maturity. Additionally, these interest rates should enter the model with as many lags as the time remaining until the maturity of the corresponding debt instruments, which implies the loss of a considerable number of observations. Both the demanding data requirements and the sacrifice of a large number of time observations from the sample prevented us from pursuing this exercise.

${ }^{5}$ For a comprehensive survey on this see for example van den Noord (1999).
} 
pute $^{6}$. An additional drawback is that this approach tends to disregard the role of shocks that have a direct effect on the budget balance ratio, which can be important for the purpose of establishing a close-to-balance criterion.

Direct approaches. There is an incipient empirical literature that directly estimates the structural balance. Bruneau and Bandt (1997) and Dalsgaard and de Serres (1999) implement the SVAR methodology to directly estimate structural balances. They include the budget balance to GDP ratio and the output growth rate in the vector of stationary variables, together with suitable identifying assumptions obtained from economic theory. The fact that SVARs perform particularly well at forecasting makes them attractive for fiscal policy analysis. Moreover, this method does not require an estimation of the output gap as a first step, nor the calculation of the elasticities of the fiscal variables with respect to output.

In particular, Dalsgaard and de Serres (1999) extend their analysis by simulating the structural shocks of their SVAR. This yields a simulated distribution of the fiscal balance which in turn is used to derive estimates of cyclically adjusted budget balances that would have to be maintained such that the actual budget balance does not surpass the reference value, with a given probability in a given time horizon.

Our approach in this paper is complementary to the SVAR approach of Dalsgaard and de Serres (1999). We use instead the unobservable components methodology to model the budget balance to GDP ratio. The main implication of our method is that, instead of assuming that the budget balance-GDP ratio is difference-stationary, we explicitly model and estimate the stochastic trend in the budget balance ratio and in output.

\subsection{The Problem of Quarterly Data Availability}

Analyzing short-term and in particular quarterly fiscal developments of the general government finances can help to anticipate risks of excessive budget balances and to give an early warning if needed. Nevertheless, the availability of these data is still far from satisfactory.

Some quarterly and even monthly fiscal data are available for most EU countries. Unfortunately, this information turns out to be of little use for short-term monitoring. This is for two main reasons: i) the data have limited coverage and ii) they are typically reported in a cash basis. The coverage of available quarterly fiscal data is usually restricted to central government, they rarely cover general government. This offers only partial information on budgetary developments. The fact that the available data do not follow national accounts definitions is also an important drawback. The discrepancy between the figures computed

\footnotetext{
${ }^{6}$ This is not the case for the modelling strategy presented in this paper.
} 
on a cash basis and on a national accounts basis can be considerable for fiscal variables. For instance, to compute figures consistent with the national accounts definitions for the budget balance requires adjusting the cash basis figures by changes in recognized claims net of changes in liabilities, disposals of state-owned firms and interest. Furthermore, heterogeneity of sources and definitions, together with differences in coverage, makes the data and therefore the analysis hardly comparable across countries. It should be noted that the new European System of National Accounts (ESA95) imposes the transmission of main aggregates at a quarterly frequency. Member states were required to deliver the main aggregates of the general government by August 1999. Some countries have done so, for very recent years, but these data are not publicly available yet.

Therefore, annual fiscal figures and in particular budget balance figures need to be interpolated to obtain the quarterly series required to monitor the budgetary discipline prescribed by the institutional framework of EMU. But is it preferable to interpolate the budget balance series in levels or to interpolate the budget balance to GDP ratio? Our view is that directly interpolating budget balance ratios should be preferred. The reason is that most of the fiscal monitoring indicators are defined as a percentage of GDP and to be effective for policy all estimates (and interpolation is a particular case) should be provided with the corresponding error bounds. Here again, directly estimating the object of interest (the budget balance to GDP ratio) and its associated uncertainty (error bounds) in a unified framework seems to be a more coherent approach. This is so, relative to other approaches where quarterly budget balance interpolated series in levels are produced, and then divided by GDP and where error bounds cannot (by construction) be reported.

There are two widely used approaches to the problem of interpolating time series in the econometric literature. The first is based on regression techniques (see Chow and Lin (1971), Fernandez (1981) and Salazar, Smith, Weale, and Wright (1997)). The second approach is that used in Harvey and Pierce (1984) and Harvey (1989) and relies on a state space representation. The model presented in this paper pursues the second approach. However, this approach has to be extended to deal with problems of interpolating a series defined as a 'ratio' of two series, and where the numerator is observed at an annual frequency while the the denominator is observed quarterly.

\section{An UC Model of the Budget Balance Ratio}

In this section we lay out an unobserved components model of the quarterly budget balance ratio with annual fiscal data and quarterly output and inflation data. This model provides an estimate of quarterly budget balance ratio figures and decomposes these quarterly figures 
into structural, cyclical, and irregular components. We model jointly the dynamics of GDP (in logs) and the budget balance ratio. GDP is modelled as the sum of a stochastic trend and a stochastic cycle. In the simplest version of our model the budget balance ratio is the sum of a stochastic trend (which is independent of trend output), a stochastic cycle which is common to the cycle of output, and a measurement error term. We can write the model as a two dimensional stochastic process of the two variable vector series, $\boldsymbol{x}_{t, u}=\left(y_{t, u}, d_{t, u}\right)^{\prime}$, $y_{t, u}$ is real GDP in logs at year $t$ and quarter $u, t=1, \ldots, T$ and $u=1, \ldots, 4 . d_{t, u}$ stands for the budget balance-to-GDP ratio at year $t$ and quarter $u$, i.e. $\frac{D_{t, u}}{Y_{t, u}^{n}}$, where $D_{t, u}$ is the budget balance in levels and $Y_{t, u}^{n}$ the nominal GDP in levels at year $t$ and quarter $u$. $\boldsymbol{x}_{t, u}$ has the following structure:

$$
\begin{aligned}
y_{t, u} & =\mu_{t, u}^{y}+\alpha \psi_{t, u} \\
d_{t, u} & =\mu_{t, u}^{d}+\Phi_{d}(L) \psi_{t, u}+\zeta_{1 t, u}
\end{aligned}
$$

where $\mu_{t, u}^{i}$ for $i=y, d$ are two independent trend component, one for real GDP and one for deficit ratios; $\Phi_{d}(L)$ is a polynomial lag operator; $\psi_{t, u}$ is the common stochastic cyclical component and finally $\zeta_{1 t, u}$ is an iid process with standard deviations $\sigma_{\zeta 1}$. The trend components are modelled as follows:

$$
\begin{aligned}
& \mu_{t, u}^{i}=\beta_{t, u}^{i}+\mu_{t, u-1}^{i}+\varepsilon_{t, u}^{i} \\
& \beta_{t, u}^{i}=\beta_{t, u-1}^{i}+\lambda_{m} \eta_{t, u}^{d}+\nu_{t, u}^{i}
\end{aligned}
$$

where $\varepsilon_{t, u}^{i}$ and $\nu_{t, u}^{i}$ are iid processes normally distributed with mean zero and standard deviation $\sigma_{\varepsilon i}$ and $\sigma_{\nu_{i}}$ respectively. $\eta_{t, u}^{d}$ is a pulse variable that attempts to capture the potential change on the slope of the budget balance ratio trend component resulting from the adoption of the Maastricht Treaty. Finally, the cyclical component will be modelled as an autoregressive process: $\Phi(L) \psi_{t}=\left(\rho_{1}+\rho_{2} L\right) \psi_{t}=\zeta_{2 t, u}$, where $\zeta_{2 t, u}$ is a normally distributed error process with zero mean and standard deviation normalized to one. The independence of the deficit and output trend is in accordance with the idea that long-run output is not demand determined, whereas the short to medium-term dynamics of output and the budget balance ratio are jointly determined.

Fiscal indicators at quarterly frequencies could be modelled together with GDP and the budget balance in a multivariate model to help to identify the cyclical and structural deficit components and improve the quality of the interpolation. Additionally, our method allows for the inclusion of exogenous variables that could add relevant information when estimating the quarterly series and/or its components. Thus, we extend (1) to incorporate the inflation rate which enables us to distinguish between cyclical fluctuations due to changes in GDP and cyclical fluctuations due to changes in inflation. The reason why some of the budget balance 
ratio fluctuations could arise from changes in inflation rather than from changes in real GDP could be that fiscal revenues and expenditures are collected and budgeted in nominal terms and expressed as ratios of nominal GDP. Additionally, marginal tax brackets are often not indexed to inflation. This is an interesting exercise that could help to asses the relevance of price/inflation stability for fiscal policy discipline.

To account for inflation fluctuations we write the model as:

$$
\begin{aligned}
& y_{t, u}=\mu_{t, u}^{y}+\alpha \psi_{t, u} \\
& d_{t, u}=\mu_{t, u}^{d}+\Phi_{d}(L) \psi_{t, u}+\Phi_{\pi}(L) \pi_{t, u}+\zeta_{1 t, u}
\end{aligned}
$$

where $\pi_{t, u}$ is inflation measured as the rate of growth of the GDP deflator. The trend and cyclical components are modelled as in (1).

\subsection{Building Quarterly Series for Budget Balance Ratios}

To estimate model (1) or, more generally, model (2) we will write it in a state space form, and then maximum likelihood estimation in combination with the Kalman filter can be implemented. How to do this is well documented in Harvey (1993). We write model (2) as:

$$
\begin{aligned}
\boldsymbol{x}_{t, u} & =\boldsymbol{A} \boldsymbol{s}_{t, u}+\boldsymbol{B} \boldsymbol{z}_{t, u}+\boldsymbol{\varepsilon}_{t, u} \\
\boldsymbol{s}_{t, u} & =\boldsymbol{C} \boldsymbol{s}_{t, u-1}+\boldsymbol{e}_{t, u}
\end{aligned}
$$

where $\boldsymbol{x}_{t, u}$ is defined as above, $\boldsymbol{s}_{t, u}$ is the vector of unobservable variables, known as the state vector, $\boldsymbol{A}, \boldsymbol{B}$ and $\boldsymbol{C}$ are matrices of parameters of order $2 \times m, 2 \times q$ and $m \times m$ respectively, where $q$ is the dimension of the vector of exogenous variables $\boldsymbol{z}_{t, u}$ changes in inflation in model (2), and $\boldsymbol{\varepsilon}_{t, u}$ and $\boldsymbol{e}_{t, u}$ are two independent zero mean processes with positive definite and finite variance matrices $\Sigma_{\varepsilon \varepsilon}$ and $\Sigma_{e e}$ respectively.

It should be noted that $y_{t, u}$ is observed every quarter, but $d_{t, u}$ is unobserved for all quarters. In order to handle this problem we need to apply a variable transformation. For this purpose we define the following artificial variable:

$$
\boldsymbol{x}_{t, j}^{a}=\sum_{i=1}^{j} \boldsymbol{W}_{t, i} \boldsymbol{x}_{t, i}
$$

where,

$$
\boldsymbol{W}_{t, i}=\left[\begin{array}{cc}
1 & 0 \\
0 & w_{t, i}
\end{array}\right] \text { and } w_{t, j}=\frac{Y_{t, j}^{n}}{\sum_{i=1}^{4} Y_{t, i}^{n}}
$$

For the fourth quarter, this new variable, is defined as $\boldsymbol{x}_{t, 4}^{a}=\left(y_{t, 4}^{a}, d_{t, 4}^{a}\right)^{\prime}$, where $d_{t, 4}^{a}$ is nothing but the annual budget balance ratio, and therefore, it is observable, and $y_{t, 4}^{a}$ is 
the cumulated sum of the logs of quarterly real GDP, also observable. Under this variable transformation it holds that $\boldsymbol{x}_{t, j+1}^{a}-\Psi_{u} I \boldsymbol{x}_{t, j}^{a}=\boldsymbol{W}_{t, j+1} \boldsymbol{x}_{t, j+1}$. Where $\Psi_{u}$ is an indicator variable which takes the value 0 if $u=1$ and the value 1 otherwise $^{7}$. This allows us to rewrite model (3) as follows:

$$
\begin{aligned}
\boldsymbol{x}_{t, u}^{a} & =\Psi_{u} I \boldsymbol{x}_{t, u-1}^{a}+\boldsymbol{W}_{t, u}\left(\boldsymbol{A} \boldsymbol{C} \boldsymbol{s}_{t, u-1}+\boldsymbol{A} \boldsymbol{e}_{t, u}+\boldsymbol{B} \boldsymbol{z}_{t, u}+\boldsymbol{\varepsilon}_{t, u}\right) \\
\boldsymbol{s}_{t, u} & =\boldsymbol{C} \boldsymbol{s}_{t, u-1}+\boldsymbol{e}_{t, u}
\end{aligned}
$$

This model can be written in state-space form and the Kalman filter can then be applied to extract the different components. The state-space representation for this model is the following:

$$
\begin{aligned}
\boldsymbol{x}_{t, u}^{a} & =\boldsymbol{Z} \boldsymbol{q}_{t, u} \\
\boldsymbol{q}_{t, u} & =\boldsymbol{N}_{t, u} \boldsymbol{q}_{t, u-1}+\boldsymbol{M}_{t, u} \boldsymbol{z}_{t, u}+\boldsymbol{R}_{t, u} \boldsymbol{v}_{t, u}
\end{aligned}
$$

where $\boldsymbol{q}_{t, u}=\left(\boldsymbol{x}_{t, u}^{a \prime}, \boldsymbol{s}_{t, u}^{\prime}\right)^{\prime}$ is the new state vector and $\boldsymbol{v}_{t, u}=\left(\boldsymbol{\varepsilon}_{t, u}^{\prime}, \boldsymbol{e}_{t, u}^{\prime}\right)^{\prime}$ is a zero mean process with covariance matrix $E\left\{\boldsymbol{v}_{t} \boldsymbol{v}_{t}^{\prime}\right\}=\boldsymbol{\Sigma}$. Details on matrices $\boldsymbol{N}_{t, u}, \boldsymbol{M}_{t, u}, \boldsymbol{R}_{t, u}, \boldsymbol{\Sigma}$ and $\boldsymbol{Z}$ are given in the appendix.

We will estimate the parameters using annual series, for this we write (4) at an annual frequency.

$$
\begin{aligned}
\boldsymbol{x}_{t, 4}^{a} & =\boldsymbol{Z} \boldsymbol{q}_{t, 4} \\
\boldsymbol{q}_{t, 4} & =\boldsymbol{N}_{t}^{4} \boldsymbol{q}_{t-1,4}+\boldsymbol{M}_{t}^{4}\left(\boldsymbol{z}_{t, 1}, \ldots, \boldsymbol{z}_{t, 4}\right)+\boldsymbol{\xi}_{t, 4}
\end{aligned}
$$

where $\boldsymbol{\xi}_{t, 4}$ is a zero mean process formed as a linear combination of the process $\boldsymbol{v}_{t, u}$, and $E\left\{\boldsymbol{\xi}_{t, 4} \boldsymbol{\xi}_{t, 4}^{\prime}\right\}=\boldsymbol{\Lambda}_{t, 4}$. Details on $\boldsymbol{N}_{t}^{4}, \boldsymbol{M}_{t}^{4}\left(\boldsymbol{z}_{t, 1}, \ldots, \boldsymbol{z}_{t, 4}\right)$ and $\boldsymbol{\Lambda}_{t, 4}$ are also in the appendix.

Once the parameters are estimated it only remains to compute the estimates of the unobserved component $\boldsymbol{q}_{t, u}$ using all available information in the sample. To do this we use a fixed interval smoothing algorithm along the lines of Ansley and Kohn (1982). Their method relies on bringing the outcome of a standard Kalman filter into a simple recursive algorithm. In our case, there is no new information on budget balance for the first three quarters, but there is new information available on output and inflation every quarter; this implies that partial updating is required in the updating equations of the Kalman filter (see the appendix).

\footnotetext{
${ }^{7}$ For a standard flow variable, it holds that $x_{t}=\sum_{i=1}^{4} x_{t, i}$, and this relationship can be exploited to redefine the problem so as to interpolate the series (see Harvey (1989)). But this does not hold for ratios.
} 


\section{Empirical Results}

\subsection{The Data}

The countries included in the study are Germany and Italy. Seasonally adjusted quarterly real GDP data and the GDP deflator are taken from OECD's Main Economic Indicators (MEI). For each country, the government budget balance ratio is constructed as the ratio of annual nominal net government lending in the country over annual nominal GDP. The source of both numerator and denominator are OECD's National Accounts. The sample period covered is $1971-2000$.

\subsection{Country results}

For each country, we estimate two specifications of the model, a basic one which does not include inflation changes, this is model 1, and another specification, model 2, where changes in inflation is included as one of the regressors, allowing us to extract a cyclical component which captures budget balance fluctuations arising from inflation fluctuations. Inflation is considered to be exogenous for the purposes of this exercise.

We report the following types of results for each country and each model. A subset of the estimated coefficients of the model (table 1), the Ljung-Box test of model specification (table 2 ), and the series with interpolated budget balance (table 4). The graphs corresponding to such series and its decomposition are in figures 1 to 4 . Additionally, the fact that confidence bounds of the government budget balance and of its components are also obtained makes it possible, on the basis of these results, to derive some valuable tools for quarterly fiscal monitoring. We calculate the safety margins that would prevent countries from breaching, under adverse conditions, the $3 \%$ deficit reference figure imposed by the Maastrich Treaty (table 3). The model also allows to perform other simulation exercises; for instance, to calculate the probability, of reaching a certain deficit ratio, e.g. figure 5 .

Estimated coefficients. Table 1 shows, for both countries, the coefficients corresponding to the effect of the underlying common cycle on log GDP, $\alpha$, and on the budget balance ratio, $\alpha_{1}$ and $\alpha_{2}$ for the current and lagged cycle respectively. $\lambda_{\pi}$ measures the effect of changes in inflation on the budget balance ratio. $\lambda_{m}$ captures the potential effect of the Maastricht Treaty and the Stability on the budget balance trend (or structural component). Finally, $\sigma_{\varepsilon y}, \sigma_{\varepsilon d}, \sigma_{\nu y}$ and $\sigma_{\nu d}$ are the estimated standard deviation of error components, $\varepsilon_{t, u}^{y}, \varepsilon_{t, u}^{d}, \nu_{t, u}^{y}$ and $\nu_{t, u}^{d}$ respectively and $\rho_{1}$ and $\rho_{2}$ are the correlation coefficients of the cycle.

The signs of the coefficients in table 1 are in general consistent with what is to be expected: the budget balance ratio is estimated as counter-cyclical in all cases, since both 
cyclical output and the cyclical budget balance ratio are positively related to the underlying common cycle. Although, the coefficient relating the budget balance ratio to the lag of the common cycle is negative, it is statistically insignificant.

Increases in inflation have a positive effect on the budget balance ratio for Germany. This finding might be due to factors like real effects of inflation when marginal income taxes are not indexed to inflation. The coefficient for Italy turns out to be negative, although not very significant. This reflects the fact that nominal GDP reacts more than government net lending to inflation changes.

In the case of Italy the estimated coefficients of the effect of the underlying common cycle on log of real GDP and on the budget balance change considerably in value from model 1 to model 2. Nevertheless, the estimated series present similar order of magnitude, see figures 3 and 4 . This is explained by the fact that the cycle estimated for model 2 displays more persistency.

According to our estimations, the introduction of the discipline imposed by the Maastricht Treaty has resulted in a positive change on the slope of the budget trend for Italy; in other terms, the structural component of the Italian budget balance has improved, while for Germany the Masstricht effect is (statistically) insignificant.

Specification test. Table 2 reports the Ljung-Box statistic to check whether the model structure is rich enough to absorb the serial correlation in the data. We compute this from the standardized prediction error residuals obtained from the Kalman Filter. A model is well specified if the hypothesis of no serial correlation tested using the Ljung-Box statistic cannot be rejected. The statistic is computed for the first 4 and 6 autocorrelations. They do not reveal any problem with our models specification.

Estimated quarterly budget balance ratio and its decomposition. Figures 1 to 4 show, for each country and each model, the estimated quarterly budget balance ratio figure and its decomposition. The first chart in each figure shows the estimated quarterly budget balance ratio together with its structural component. The second chart is the estimated cyclical component of the budget balance ratio arising from fluctuations in real activity and the third and final chart is the estimated component which captures the cyclical comovements of the budget balance ratio and inflation.

Inspection of these figures reveals a number of interesting results. As a general rule, we do not find large and persistent deviations of the budget balance ratio from the structural figure. Comparing to the usual results from the 2-step method for estimating structural budget balances (see section 2), we obtain a structural deficit ratio which is relatively less 
smooth and a cyclical component which appears to be relatively less persistent. It should be noted that there is not one commonly agreed decomposition of actual public budget balance between its cyclical and structural components. While estimates of the structural budget balance from the 2-step method and our UC approach cannot be compared through a statistical specification test ${ }^{8}$, the qualitatively different results from the 2-step approach and our unobserved components approach has a clear policy implication. This is related to the degree of prudence that should be incorporated in measures of the structural budget balance ratio. It is clear that alternative decompositions have different implications in terms of deriving a prudent medium-term budget balance ratio target which leaves a prudent margin for fluctuations in the actual ratio. In this sense decompositions which attribute the great bulk of the balance ratio to the structural component should be regarded as prudent, since approximations of the actual deficit to the $3 \%$ bound are less often interpreted as temporary cyclical fluctuations.

The estimated cyclical component of the quarterly balance ratio due to inflation changes is positive for Germany. When comparing results from model 1 and model 2, one can see that taking into account inflation fluctuations does not modify substantially the fluctuation pattern of the cyclical component due to real activity but slightly lowers the level of the structural component (except for the most recent years of the sample). In the case of Italy, changes in inflation seem to be responsible for an important part of the cyclical fluctuations. When inflation is taken into account explicitly the cyclical component due to real activity smoothes considerably and the structural component is shifted upwards once we control from inflation. The results for Italy should be taken with caution because the coefficient of changes in inflation is not very significant.

In general, the assessment of the fiscal stance could benefit from incorporating information on inflation, in addition to information on output, since it could have a considerable impact on the budget balance ratio and its components.

Estimated safety margins. On the basis of the results from our model it is possible to calculate safety margins for the budget balance ratio which should be targeted in the medium term to avoid breaching the $3 \%$ reference figure imposed by the Maastricht Treaty even under adverse conditions. Although several alternative safety margin figures may be constructed depending on how the adverse cyclical scenario is characterized, we focus on two possible definitions, which, for concreteness, we label respectively the worst recession margin and the 2-standard deviations recession margin.

\footnotetext{
${ }^{8}$ This is because the 2-step method does not follow a fully statistical approach.
} 
The worst recession margin is defined as the structural deficit which will be safe to meet the required $3 \%$ bound for the deficit ratio when adverse cyclical conditions are taken as the largest realized cyclical deficit for the country, i.e. the minimum value of the cyclical components (real, due to inflation and total) of the budget balance figures. ${ }^{9}$ In the 2-standard-deviations recession margin the scenario for the adverse cyclical conditions is differently defined. For cyclical component due to real activity it is taken as the "average volatility" of the budget balance ratio. The latter is measured as twice the standard deviation of the cyclical budget balance ratio. The inflation cyclical components scenario is defined as the one corresponding to a inflation of $2 \%$. This scenario attempts to reflect what could be a likely situation for the near future instead of being exclusively based on past realizations. Table 3 shows the values of these two safety margins in our model. Results in table 3 are reported for the total cyclical component, i.e. real activity plus the inflation component, and also for each one of these two cyclical components. In the case of Germany, model 1, in which inflation fluctuations are not taken into account as sources of cyclical fluctuations, suggests that to avoid overpassing the 3\% Maastricht figure, fiscal authorities should maintain the structural budget balance literally close to balance according to the worst recession safety margin and below -1.2\% according to the 2-standard deviations recession safety criteria. Taking into account inflation fluctuations, model 2 suggests that the target for the government should be $1 \%$ structural deficit (worst recession safety margin) and they could afford even $3 \%$ structural deficit under the 2-standard deviations recession margin, because for this scenario the cyclical component is close to balance.

For the Italian case the dependence of budget balance figures on cyclical factors is stronger than in the case of Germany. The safe structural budget balance figures are respectively $1 \%$ and $-0.6 \%$ when inflation is not explicitly taken into account and $2 \%$ superavit and close to balance when inflation is taken into account. It should be mentioned that these calculations do not account for objectives such as reducing debt or taking precautions for the problem of ageing population, which could require larger safety margins.

Other exercises could be easily implemented on the basis of our results; as an example, figure 5 shows the probability for the structural deficit to go lower than $-2 \%$ for Germany and $-9 \%$ for Italy one quarter ahead.

\footnotetext{
${ }^{9}$ Previous estimates of safety margins have been calculated following two approaches. The simplest approach has consisted on taking the maximum negative output gap and applying estimates of the the overall elasticity of budget balances to output as in Buti, Franco, and Ongena (1998) where they find that structural deficits between $0 \%$ and $1 \%$ both Germany and Italy from exceeding the $3 \%$ deficit. A second approach, more similar to ours, is that in Dalsgaard and de Serres (1999), they implement the SVAR methodology to directly estimate structural balances and perform some stochastic simulations to find safety margins for the EU countries. They find that for both Italy and Germany structural deficits of around 1-1.5\% will be safe.
} 


\section{$5 \quad$ Summary and conclusions}

The monitoring of countries' fiscal stances has received increased attention in recent years, particularly in the EMU, where the adoption of a common currency requires introducing limits on the budget balance ratio of member countries and calls for multilateral surveillance among them. In the current context of EMU the need for effective tools for short-term monitoring fiscal discipline cannot be over-emphasized.

The standard indicator used for monitoring fiscal discipline in Europe is the structural budget balance, which must be estimated for actual data. This indicator suffers from two main drawbacks. There is no consensus on how to estimate it and it is estimated at an annual frequency. In fact, the availability of fiscal quarterly data in EU countries is still far from satisfactory.

This paper develops a modelling framework to estimate quarterly budget balance ratios together with their decomposition into cyclical and cyclically adjusted components when fiscal figures are only available at an annual frequency. In addition, it provides interesting results for Germany and Italy.

The decomposition obtained from our statistical approach is a useful complement to existing measures for two main reasons. First, it easily derives uncertainty bounds around the estimated structural (and cyclical) budget balance ratios, which is an additional important element in a complete assessment of the fiscal stance. Second, our approach can easily incorporate the effect of additional determinants of the fiscal stance in the overall assessment, like inflation, proxies to population ageing, interest rates, etc. We extend the model to incorporate inflation which enables us to identify cyclical fluctuations arising from price dynamics. This also serves to improve the short to medium-term forecast of the budget balance ratio by incorporating available information on price developments.

Interestingly, our analysis yields objective, well-defined and still easily computable figures for the structural budget balance ratio, that would have to be targeted to fulfil the Maastricht criteria in the future, with any given probability.

Given these properties, we regard the modelling tools laid out in this paper as providing a very useful framework to enhance the effectiveness of fiscal stance monitoring. 


\section{A Appendix}

A.1 State Space Representation: Quarterly frequency

$$
\begin{gathered}
\boldsymbol{M}_{t, u}=\left[\begin{array}{c}
\boldsymbol{W}_{t, u} \boldsymbol{B} \\
\mathbf{0}
\end{array}\right] \\
\boldsymbol{N}_{t, u}=\left[\begin{array}{cc}
\Psi_{t, u} \boldsymbol{I} & \boldsymbol{W}_{t, u} \boldsymbol{A} \boldsymbol{C} \\
\mathbf{0} & \boldsymbol{C}
\end{array}\right] \\
\boldsymbol{R}_{t, u}=\left[\begin{array}{cc}
\boldsymbol{W}_{t, u} & \boldsymbol{W}_{t, u} \boldsymbol{A} \\
\mathbf{0} & \boldsymbol{I}
\end{array}\right] \quad \boldsymbol{\Sigma}=\left[\begin{array}{cc}
\boldsymbol{\Sigma}_{\varepsilon \varepsilon} & \mathbf{0} \\
\mathbf{0} & \boldsymbol{\Sigma}_{e e}
\end{array}\right] \quad \boldsymbol{Z}=\left[\begin{array}{ll}
\boldsymbol{I} & 0
\end{array}\right]
\end{gathered}
$$

\section{A.2 State Space Representation: Annual frequency}

$$
\begin{gathered}
\boldsymbol{\Lambda}_{t, 4}=\boldsymbol{R}_{t, 4} \boldsymbol{\Sigma} \boldsymbol{R}_{t, 4}+\sum_{i=1}^{3} \boldsymbol{N}_{t}^{i} \boldsymbol{R}_{t, 4-i} \boldsymbol{\Sigma} \boldsymbol{R}_{t, 4-i}^{\prime} \boldsymbol{N}_{t}^{i \prime} \\
\boldsymbol{N}_{t}^{k}=\prod_{i=0}^{k-1} \boldsymbol{N}_{t, 4-i} \\
\boldsymbol{M}_{t}^{4}\left(\boldsymbol{z}_{t, 1}, \ldots, \boldsymbol{z}_{t, 4}\right)=\boldsymbol{M}_{t, 4} \boldsymbol{z}_{t, 4}+\sum_{i=1}^{3} \boldsymbol{N}_{t}^{i} \boldsymbol{M}_{t, 4-i} \boldsymbol{z}_{t, 4-i}
\end{gathered}
$$

\section{A.3 Kalman Filtering with Partial Updating}

From equation (4) above we can see that the vector $\left(\boldsymbol{q}_{t, u}^{\prime} \boldsymbol{x}_{t, u}^{a \prime}\right)^{\prime}$ is multivariate normal with mean $\left(\boldsymbol{q}_{t, u \mid t, u-1}^{\prime} \boldsymbol{Z} \boldsymbol{q}_{t, u \mid t, u-1}^{\prime}\right)^{\prime}$ and covariance matrix

$$
\left(\begin{array}{cc}
\boldsymbol{P}_{t, u \mid t, u-1} & \boldsymbol{P}_{t, u \mid t, u-1} \boldsymbol{Z}^{\prime} \\
\boldsymbol{Z} \boldsymbol{P}_{t, u \mid t, u-1} & \boldsymbol{Z} \boldsymbol{P}_{t, u \mid t, u-1} \boldsymbol{Z}^{\prime}
\end{array}\right)
$$

where $\boldsymbol{q}_{t, u \mid t, u-1}$ and $\boldsymbol{P}_{t, u \mid t, u-1}$ are given by the so called prediction equations:

$$
\begin{aligned}
\boldsymbol{q}_{t, u \mid t, u-1} & =\boldsymbol{N}_{t, u} \boldsymbol{q}_{t, u-1 \mid t, u-1}+\boldsymbol{M}_{t, u} \boldsymbol{z}_{t, u} \\
\boldsymbol{P}_{t, u \mid t, u-1} & =\boldsymbol{N}_{t, u} \boldsymbol{P}_{t, u-1 \mid t, u-1} \boldsymbol{N}_{t, u}^{\prime}+\boldsymbol{R}_{t, u} \boldsymbol{\Sigma} \boldsymbol{R}_{t, u}^{\prime}
\end{aligned}
$$

Based on the properties of the multivariate normal distribution, the distribution of $\boldsymbol{q}_{t, u}$ conditional on $\boldsymbol{J}_{u} \boldsymbol{x}_{t, u}^{a}$, where $\boldsymbol{J}_{u}$ is a constant matrix to be defined below, is multivariate normal with mean and covariance matrix given by the so called updating equations:

$$
\begin{aligned}
\boldsymbol{q}_{t, u \mid t, u} & =\boldsymbol{q}_{t, u \mid t, u-1}+\boldsymbol{P}_{t, u \mid t, u-1} \boldsymbol{Z}^{\prime} \boldsymbol{J}_{u}^{\prime} \boldsymbol{F}_{t, u}^{-1} \boldsymbol{J}_{u}\left(\boldsymbol{x}_{t, u}^{a}-\boldsymbol{Z} \boldsymbol{q}_{t, u \mid t, u-1}\right) \\
\boldsymbol{P}_{t, u \mid t, u} & =\boldsymbol{P}_{t, u \mid t, u-1}-\boldsymbol{P}_{t, u \mid t, u-1} \boldsymbol{Z}^{\prime} \boldsymbol{J}_{u}^{\prime} \boldsymbol{F}_{t, u}^{-1} \boldsymbol{J}_{u} \boldsymbol{Z} \boldsymbol{P}_{t, u \mid t, u-1}
\end{aligned}
$$

where $\boldsymbol{F}_{t, u}$ is the mean square of the prediction error, $\boldsymbol{x}_{t, u}^{a}-\boldsymbol{Z} \boldsymbol{q}_{t, u \mid t, u-1}$, and given by $\boldsymbol{F}_{t, u}=$ $\boldsymbol{J}_{u} \boldsymbol{Z} \boldsymbol{P}_{t, u \mid t, u-1} \boldsymbol{Z}^{\prime} \boldsymbol{J}_{u}^{\prime}$. Note that $\boldsymbol{x}_{t, u}^{a}$ is fully observed on the fourth quarter, but only partially observed over the first three quarters, i.e. GDP is observed quarterly, but the budget balance is observed only annually. This fact can be easily accommodated by defining $\boldsymbol{J}_{u}$ as a $2 \times 2$ identity matrix if $u=4$, and as matrix [ 110 ] otherwise. Note full knowledge of the path for the exogenous variables $\boldsymbol{z}_{t, u}$ has been assumed, otherwise expectations on this variable should replace their value in the equations above. 


\section{A.4 The Fixed Interval Smoothing Algorithm}

Denote as $\boldsymbol{q}_{t, u \mid T}$ the estimate of $\boldsymbol{q}_{t, u}$ given the information until time $T$.The recursive fixed interval smoothing algorithm of Ansley and Kohn (1982) is as follows.

$$
\begin{aligned}
\boldsymbol{q}_{t, u \mid T, 4} & =\boldsymbol{q}_{t, u \mid t, u}+\boldsymbol{H}_{t, u}\left(\boldsymbol{q}_{t, u+1 \mid T, 4}-\boldsymbol{N}_{t, u+1} \boldsymbol{q}_{t, u \mid t, u}-\boldsymbol{M}_{t, u+1} \boldsymbol{z}_{t, u+1}\right) \\
\boldsymbol{P}_{t, u \mid T, 4} & =\boldsymbol{P}_{t, u \mid t, u}-\boldsymbol{H}_{t, u}\left(\boldsymbol{P}_{t, u+1 \mid t, u}-\boldsymbol{P}_{t, u+1 \mid T, 4}\right) \boldsymbol{H}_{t, u}^{\prime}
\end{aligned}
$$

where $\boldsymbol{H}_{t, u}=\boldsymbol{P}_{t, u \mid t, u} \boldsymbol{N}_{t, u+1}^{\prime} \boldsymbol{P}_{t, u+1 \mid t, u}$; and where $\boldsymbol{q}_{t, u \mid t, u}, \boldsymbol{P}_{t, u \mid t, u}$ and $\boldsymbol{P}_{t, u+1 \mid t, u}$ are obtained from the Kalman filter recursions. 


\section{References}

Alesina, A., And R. Perotti (1996): "Fiscal Discipline and the Budget Process," American Economic Review Papers and Proceedings, 86, 401-407.

Ansley, C. F., And R. Kohn (1982): "A geometrical derivation of the fixed inteval smoothing algorithm," Biometrika, 69, 486-487.

Blanchard, O. (1993): "Suggestions for a New Set of Fiscal Indicators," OECD Working paper No 79, April. Also in The Political Economy of Debt, H.A.A. Verbon and F. Van Winden, editors, North Holland, 1993, pp. 307-324.

Bruneau, C., and O. D. Bandt (1997): "Fiscal Policy in the Transition to Monetary Union: a Structural VAR Model," mimeo.

Buti, M. D., D. Franco, and H. Ongena (1998): "Fiscal discipline and flexibility in EMU: the implementation of the Stability and Growth Pact," Oxford Review of Economic Policy, 14, 81-97.

Chow, G. C., AND A. L. Lin (1971): "Best Linear Unbiased Interpolation, Distribution and Extrapolation of Time Series by Related Series," Review of Economics and Statistics, $53,372-375$.

DalsgaArd, T., And A. DE Serres (1999): "Estimating Prudetial Bugetary Margins for EU Countries: a Simulated SVAR Model Approach," OECD Working Paper no. 99.8.

ECB (2002): "The Operation of Automatic Fiscal Stabilisers in the Euro Area," ECB Monthly Bulletin, April 2002, pp. 33-46.

European-Commission (2000): "Public Finances in EMU," European Economy, No 3.

Fernandez, R. (1981): "A methodological note on the estimation of time series," Review of Economics and Statistics, 63, 471-478.

Harvey, A. C. (1989): Forecasting, Structural Time Series Models and the Kalman Filter. Cambridge University Press.

- (1993): Time Series Models. Harvester and Wheatsheaf.

Harvey, A. C., ANd R. G. PierCe (1984): "Estimating missing observations in economic time series," Journal of the American Statistical Association, 79, 125-131. 
Salazar, E., R. J. Smith, M. R. Weale, And S. Wright (1997): “A Monthly Indicator of GDP," Working Paper No 127, National Institute of Economic and Social Research.

TAYlor, J. B. (2000): "Reassessing Discretionary Fiscal Policy," Journal of Economic Perspectives, 14, 21-36.

VAn Den Noord, P. (1999): "The Size and Role of Automatic Fiscal Stabilizers in the 1990's and Beyond," OECD Working Paper no. 2000.3. 
Table 1: Estimation Results. ${ }^{a}$

\begin{tabular}{|c|c|c|c|c|c|c|c|c|}
\hline \multirow[b]{3}{*}{ parameter } & \multicolumn{4}{|c|}{ Germany } & \multicolumn{4}{|c|}{ Italy } \\
\hline & \multicolumn{2}{|c|}{ model 1} & \multicolumn{2}{|c|}{ model 2} & \multicolumn{2}{|c|}{ model 1} & \multicolumn{2}{|c|}{ model 2} \\
\hline & value & $t-s t a t$ & value & $t-s t a t$ & value & $t-s t a t$ & value & $t-s t a t$ \\
\hline$\alpha$ & 0.0127 & 2.148 & 0.0130 & 2.327 & 0.0227 & 2.519 & 0.0046 & 1.596 \\
\hline$\alpha_{1}$ & 0.0170 & 2.961 & 0.0139 & 2.304 & 0.0333 & 3.042 & 0.0077 & 2.681 \\
\hline$\alpha_{2}$ & -0.0041 & -0.330 & -0.0078 & -1.401 & -0.0171 & -1.232 & -0.0007 & -0.300 \\
\hline$\rho_{1}$ & -0.5298 & -8.592 & -0.5304 & -9.194 & -0.1572 & -0.332 & 0.9383 & 10.871 \\
\hline$\rho_{2}$ & -0.8965 & -19.735 & -0.9051 & -23.455 & -0.8232 & -1.892 & -0.9351 & -10.892 \\
\hline$\sigma_{\varepsilon y}$ & -0.0086 & -10.711 & -0.0085 & -9.380 & 0.0075 & 2.208 & 0.0077 & 3.975 \\
\hline$\sigma_{\nu y}$ & 0.0 & - & 0.0 & - & 0.0003 & 0.886 & 0.0003 & 1.230 \\
\hline$\sigma_{\varepsilon d}$ & 0.0030 & 3.654 & 0.0031 & 4.913 & 0.0 & - & 0.0 & - \\
\hline$\sigma_{\nu d}$ & 0.0 & - & 0.0 & - & 0.0002 & 1.005 & 0.0005 & 2.623 \\
\hline$\sigma_{\zeta 1}$ & 0.0 & - & 0.0 & - & 0.0 & - & 0.0 & - \\
\hline$\lambda_{m}$ & 0.0016 & 0.482 & 0.0017 & 0.950 & 0.0025 & 1.688 & 0.0030 & 2.195 \\
\hline$\lambda_{\pi}$ & - & - & 0.8131 & 2.510 & - & - & -0.4592 & -1.648 \\
\hline
\end{tabular}

${ }^{a}$ Note that $\Phi_{d}(L)=\alpha_{1}+\alpha_{2} L$ and $\Phi_{\pi}(L)=\lambda_{\pi}$, all other coefficients are as defined in the text. 
Table 2: Specification Tests: Ljung Box Statistic.

\begin{tabular}{||c|cc|cc||cc|cc||}
\hline \hline & \multicolumn{4}{|c||}{ Germany } & \multicolumn{4}{c||}{ Italy } \\
\hline & \multicolumn{2}{|c|}{ model 1 } & \multicolumn{2}{|c||}{ model 2 } & \multicolumn{2}{c||}{ model 1 } & \multicolumn{2}{c||}{ model 2 } \\
& $\mathrm{Q}(4)$ & $\mathrm{Q}(6)$ & $\mathrm{Q}(4)$ & $\mathrm{Q}(6)$ & $\mathrm{Q}(4)$ & $\mathrm{Q}(6)$ & $\mathrm{Q}(4)$ & $\mathrm{Q}(6)$ \\
\hline \multirow{3}{*}{ stat } & & \multicolumn{1}{|c|}{} & \multicolumn{1}{|c||}{} & & & & \\
l.s. & 0.034 & 0.142 & 0.019 & 0.118 & 0.012 & 0.014 & 0.007 & 0.075 \\
\hline \hline
\end{tabular}

Table 3: Safety margins for Budget Balance Ratios.

\begin{tabular}{|c|c|c|c|c|c|c|}
\hline & & & $\operatorname{Min}^{a}$ & $\begin{array}{l}\text { Worst Recession } \\
\text { safety } \operatorname{margin}^{b}\end{array}$ & $2 \sigma$ & $\begin{array}{c}\text { 2-standard-deviations } \\
\text { safety margin }\end{array}$ \\
\hline \multirow[t]{2}{*}{ Germany } & model 1 & $\begin{array}{c}\text { Real Activity } \\
\text { Inflation } \\
\text { Total } \\
\end{array}$ & $\begin{array}{c}-0.0308 \\
- \\
-0.0308 \\
\end{array}$ & $\begin{array}{c}0.0008 \\
- \\
0.0008 \\
\end{array}$ & $\begin{array}{c}-0.0182 \\
- \\
-0.0182 \\
\end{array}$ & $\begin{array}{c}-0.0118 \\
- \\
-0.0118 \\
\end{array}$ \\
\hline & model 2 & $\begin{array}{c}\text { Real Activity } \\
\text { Inflation } \\
\text { Total } \\
\end{array}$ & $\begin{array}{l}-0.0289 \\
-0.0008 \\
-0.0200 \\
\end{array}$ & $\begin{array}{l}-0.0011 \\
-0.0292 \\
-0.0100 \\
\end{array}$ & $\begin{array}{c}-0.0167 \\
0.0163 \\
-0.0005 \\
\end{array}$ & $\begin{array}{l}-0.0133 \\
-0.0463 \\
-0.0295\end{array}$ \\
\hline \multirow[t]{2}{*}{ Italy } & model 1 & $\begin{array}{c}\text { Real Activity } \\
\text { Inflation } \\
\text { Total }\end{array}$ & $\begin{array}{c}-0.0441 \\
- \\
-0.0441\end{array}$ & $\begin{array}{c}0.0141 \\
- \\
0.0141\end{array}$ & $\begin{array}{l}-0.0241 \\
-0.0241\end{array}$ & $\begin{array}{c}-0.0059 \\
- \\
-0.0059\end{array}$ \\
\hline & model 2 & $\begin{array}{c}\text { Real Activity } \\
\text { Inflation } \\
\text { Total }\end{array}$ & $\begin{array}{l}-0.0452 \\
-0.0357 \\
-0.0592\end{array}$ & $\begin{array}{l}0.0152 \\
0.0057 \\
0.0292\end{array}$ & $\begin{array}{l}-0.0217 \\
-0.0092 \\
-0.0309\end{array}$ & $\begin{array}{c}-0.0083 \\
-0.0208 \\
0.0009\end{array}$ \\
\hline
\end{tabular}

${ }^{a}$ Min gives the minimum value for a particular cyclical component.

${ }^{b}$ Worst recession safety budget balance is the difference between -0.03 Maastrich limit and the largest cyclical component of budget balances for each country. $2 \sigma$ is equal to two standard errors of the cyclical component, while 2-standard deviations safety deficit is the difference between the Maastrich reference value and two standard errors of the country's cyclical component. 
Table 4: Model Interpolated Quarterly Deficit Ratio Series.

\begin{tabular}{||c|cc|cc||}
\hline \hline & \multicolumn{2}{|c||}{} & \multicolumn{2}{c||}{ Italy } \\
year & model 1 & model 2 & model 1 & model 2 \\
\hline \hline & & & & \\
1970Q1 & -0.0251 & -0.0214 & - & - \\
1970Q2 & 0.0209 & 0.0294 & - & \\
1970Q3 & 0.0040 & -0.0005 & - & - \\
1970Q4 & 0.0069 & -0.0007 & - & - \\
1971Q1 & -0.0028 & 0.0058 & -0.0306 & -0.0627 \\
1971Q2 & 0.0022 & 0.0022 & -0.0671 & -0.0541 \\
1971Q3 & 0.0030 & 0.0006 & -0.0597 & -0.0506 \\
1971Q4 & -0.0087 & -0.0147 & -0.0693 & -0.0599 \\
1972Q1 & 0.0053 & 0.0066 & -0.0717 & -0.0771 \\
1972Q2 & -0.0064 & -0.0107 & -0.0878 & -0.0823 \\
1972Q3 & -0.0115 & -0.0073 & -0.0778 & -0.0817 \\
1972Q4 & -0.0078 & -0.0091 & -0.0925 & -0.0887 \\
1973Q1 & 0.0285 & 0.0352 & -0.0958 & -0.0938 \\
1973Q2 & 0.0071 & -0.0020 & -0.0758 & -0.0800 \\
1973Q3 & 0.0091 & 0.0068 & -0.0674 & -0.0727 \\
1973Q4 & 0.0021 & 0.0067 & -0.0673 & -0.0600 \\
1974Q1 & -0.0008 & -0.0062 & -0.0722 & -0.0849 \\
1974Q2 & -0.0171 & -0.0157 & -0.0648 & -0.0656 \\
1974Q3 & -0.0026 & -0.0022 & -0.0664 & -0.0651 \\
1974Q4 & -0.0302 & -0.0265 & -0.0966 & -0.0844 \\
1975Q1 & -0.0565 & -0.0609 & -0.1347 & -0.1242 \\
1975Q2 & -0.0489 & -0.0459 & -0.1272 & -0.1378 \\
1975Q3 & -0.0521 & -0.0559 & -0.1146 & -0.1275 \\
1975Q4 & -0.0607 & -0.0556 & -0.1195 & -0.1067 \\
1976Q1 & -0.0295 & -0.0342 & -0.1021 & -0.0926 \\
1976Q2 & -0.0321 & -0.0321 & -0.1009 & -0.1097 \\
1976Q3 & -0.0490 & -0.0413 & -0.0889 & -0.0894 \\
1976Q4 & -0.0223 & -0.0253 & -0.0876 & -0.0877 \\
1977Q1 & -0.0240 & -0.0277 & -0.0733 & -0.0805 \\
1977Q2 & -0.0293 & -0.0267 & -0.0823 & -0.0815 \\
1977Q3 & -0.0314 & -0.0318 & -0.0951 & -0.0836 \\
1977Q4 & -0.0099 & -0.0085 & -0.0832 & -0.0880 \\
1978Q1 & -0.0274 & -0.0276 & -0.0979 & -0.1028 \\
1978Q2 & -0.0206 & -0.0180 & -0.0960 & -0.1044 \\
1978Q3 & -0.0282 & -0.0245 & -0.1099 & -0.1020 \\
1978Q4 & -0.0187 & -0.0247 & -0.1012 & -0.0960 \\
1979Q1 & -0.0321 & -0.0308 & -0.0984 & -0.0949 \\
1979Q2 & -0.0096 & -0.0144 & -0.1096 & -0.1014 \\
1979Q3 & -0.0326 & -0.0270 & -0.0998 & -0.1041 \\
1979Q4 & -0.0260 & -0.0281 & -0.0854 & -0.0923 \\
1980Q1 & -0.0145 & -0.0131 & -0.0804 & -0.0855 \\
1980Q2 & -0.0347 & -0.0328 & -0.0826 & -0.0786 \\
1980Q3 & -0.0285 & -0.0291 & -0.0879 & -0.0782 \\
1980Q4 & -0.0352 & -0.0379 & -0.0808 & -0.0893 \\
\hline \hline & & & & \\
\hline
\end{tabular}


Table 4.cont: Model Interpolated Quarterly Deficit Ratio Series.

\begin{tabular}{||c|cc|cc||}
\hline \hline & & & \multicolumn{2}{c||}{} \\
year & model 1 & model 2 & model 1 & model 2 \\
\hline \hline & & & & \\
1981Q1 & -0.0324 & -0.0350 & -0.1151 & -0.1095 \\
1981Q2 & -0.0386 & -0.0371 & -0.1081 & -0.1181 \\
1981Q3 & -0.0313 & -0.0313 & -0.1212 & -0.1174 \\
1981Q4 & -0.0410 & -0.0398 & -0.1086 & -0.1080 \\
1982Q1 & -0.0301 & -0.0307 & -0.1061 & -0.1025 \\
1982Q2 & -0.0233 & -0.0272 & -0.1101 & -0.1109 \\
1982Q3 & -0.0374 & -0.0330 & -0.1143 & -0.1169 \\
1982Q4 & -0.0383 & -0.0380 & -0.1144 & -0.1147 \\
1983Q1 & -0.0193 & -0.0180 & -0.1014 & -0.1059 \\
1983Q2 & -0.0212 & -0.0300 & -0.1157 & -0.1063 \\
1983Q3 & -0.0366 & -0.0304 & -0.1063 & -0.1031 \\
1983Q4 & -0.0222 & -0.0208 & -0.0945 & -0.1025 \\
1984Q1 & -0.0072 & -0.0116 & -0.1057 & -0.1050 \\
1984Q2 & -0.0395 & -0.0440 & -0.1194 & -0.1165 \\
1984Q3 & -0.0175 & -0.0104 & -0.1170 & -0.1186 \\
1984Q4 & -0.0116 & -0.0100 & -0.1154 & -0.1174 \\
1985Q1 & -0.0237 & -0.0270 & -0.1290 & -0.1287 \\
1985Q2 & -0.0133 & -0.0141 & -0.1197 & -0.1234 \\
1985Q3 & 0.0010 & 0.0058 & -0.1186 & -0.1199 \\
1985Q4 & -0.0092 & -0.0101 & -0.1235 & -0.1189 \\
1986Q1 & -0.0392 & -0.0338 & -0.1215 & -0.1199 \\
1986Q2 & 0.0003 & 0.0024 & -0.1098 & -0.1162 \\
1986Q3 & -0.0085 & -0.0098 & -0.1107 & -0.1102 \\
1986Q4 & -0.0049 & -0.0108 & -0.1129 & -0.1087 \\
1987Q1 & -0.0437 & -0.0404 & -0.1140 & -0.1100 \\
1987Q2 & -0.0096 & -0.0070 & -0.1009 & -0.1097 \\
1987Q3 & -0.0121 & -0.0179 & -0.1162 & -0.1085 \\
1987Q4 & -0.0094 & -0.0093 & -0.1069 & -0.1096 \\
1988Q1 & -0.0279 & -0.0313 & -0.1029 & -0.1059 \\
1988Q2 & -0.0228 & -0.0204 & -0.1061 & -0.1048 \\
1988Q3 & -0.0171 & -0.0176 & -0.1096 & -0.1068 \\
1988Q4 & -0.0163 & -0.0148 & -0.1087 & -0.1099 \\
1989Q1 & 0.0004 & 0.0010 & -0.0979 & -0.1022 \\
1989Q2 & 0.0135 & 0.0078 & -0.1006 & -0.0971 \\
1989Q3 & -0.0095 & -0.0098 & -0.0999 & -0.0951 \\
1989Q4 & 0.0002 & 0.0057 & -0.0937 & -0.0976 \\
1990Q1 & -0.0093 & -0.0079 & -0.1028 & -0.1067 \\
1990Q2 & -0.0238 & -0.0251 & -0.1099 & -0.1092 \\
1990Q3 & -0.0257 & -0.0212 & -0.1057 & -0.1129 \\
1990Q4 & -0.0206 & -0.0251 & -0.1232 & -0.1128 \\
1991Q1 & -0.0158 & -0.0226 & -0.0950 & -0.1044 \\
1991Q2 & -0.0301 & -0.0297 & -0.1069 & -0.0997 \\
1991Q3 & -0.0426 & -0.0450 & -0.1005 & -0.0988 \\
\hline \hline & -0.0300 & -0.0214 & -0.0976 & -0.0972 \\
\hline
\end{tabular}


Table 4.cont: Model Interpolated Quarterly Deficit Ratio Series.

\begin{tabular}{||c|cc|cc||}
\hline \hline & \multicolumn{2}{|c|}{ Germany } & \multicolumn{2}{c||}{ Italy } \\
year & model 1 & model 2 & model 1 & model 2 \\
\hline \hline & & & & \\
1992Q1 & -0.0116 & -0.0185 & -0.0903 & -0.0944 \\
1992Q2 & -0.0340 & -0.0309 & -0.0932 & -0.0915 \\
1992Q3 & -0.0318 & -0.0289 & -0.0978 & -0.0946 \\
1992Q4 & -0.0245 & -0.0235 & -0.0974 & -0.0982 \\
1993Q1 & -0.0322 & -0.0327 & -0.1008 & -0.1004 \\
1993Q2 & -0.0338 & -0.0322 & -0.0932 & -0.0979 \\
1993Q3 & -0.0257 & -0.0277 & -0.0967 & -0.0903 \\
1993Q4 & -0.0330 & -0.0322 & -0.0853 & -0.0874 \\
1994Q1 & -0.0192 & -0.0193 & -0.0960 & -0.0921 \\
1994Q2 & -0.0277 & -0.0294 & -0.0879 & -0.0920 \\
1994Q3 & -0.0243 & -0.0248 & -0.0893 & -0.0916 \\
1994Q4 & -0.0254 & -0.0231 & -0.0902 & -0.0876 \\
1995Q1 & -0.0349 & -0.0351 & -0.0670 & -0.0739 \\
1995Q2 & -0.0296 & -0.0280 & -0.0807 & -0.0772 \\
1995Q3 & -0.0331 & -0.0309 & -0.0806 & -0.0792 \\
1995Q4 & -0.0350 & -0.0387 & -0.0754 & -0.0734 \\
1996Q1 & -0.0457 & -0.0425 & -0.0650 & -0.0702 \\
1996Q2 & -0.0287 & -0.0303 & -0.0831 & -0.0774 \\
1996Q3 & -0.0317 & -0.0333 & -0.0662 & -0.0731 \\
1996Q4 & -0.0308 & -0.0307 & -0.0698 & -0.0632 \\
1997Q1 & -0.0327 & -0.0335 & -0.0428 & -0.0408 \\
1997Q2 & -0.0254 & -0.0268 & -0.0196 & -0.0242 \\
1997Q3 & -0.0276 & -0.0275 & -0.0261 & -0.0186 \\
1997Q4 & -0.0227 & -0.0206 & -0.0199 & -0.0247 \\
1998Q1 & -0.0159 & -0.0172 & -0.0346 & -0.0313 \\
1998Q2 & -0.0240 & -0.0240 & -0.0286 & -0.0323 \\
1998Q3 & -0.0204 & -0.0208 & -0.0200 & -0.0250 \\
1998Q4 & -0.0220 & -0.0203 & -0.0299 & -0.0245 \\
1999Q1 & -0.0107 & -0.0114 & -0.0260 & -0.0244 \\
1999Q2 & -0.0209 & -0.0190 & -0.0186 & -0.0170 \\
1999Q3 & -0.0122 & -0.0137 & -0.0156 & -0.0164 \\
1999Q4 & -0.0131 & -0.0127 & -0.0103 & -0.0126 \\
2000Q1 & -0.0111 & -0.0130 & -0.0125 & -0.0150 \\
2000Q2 & -0.0051 & -0.0064 & -0.0161 & -0.0162 \\
2000Q3 & -0.0115 & -0.0100 & -0.0191 & -0.0185 \\
2000Q4 & -0.0136 & -0.0120 & -0.0137 & -0.0117 \\
\hline \hline & & & &
\end{tabular}


Figure 1: Quarterly Deficit Series Decomposition. Germany. Model 1.

Quarterly Deficit Ratio
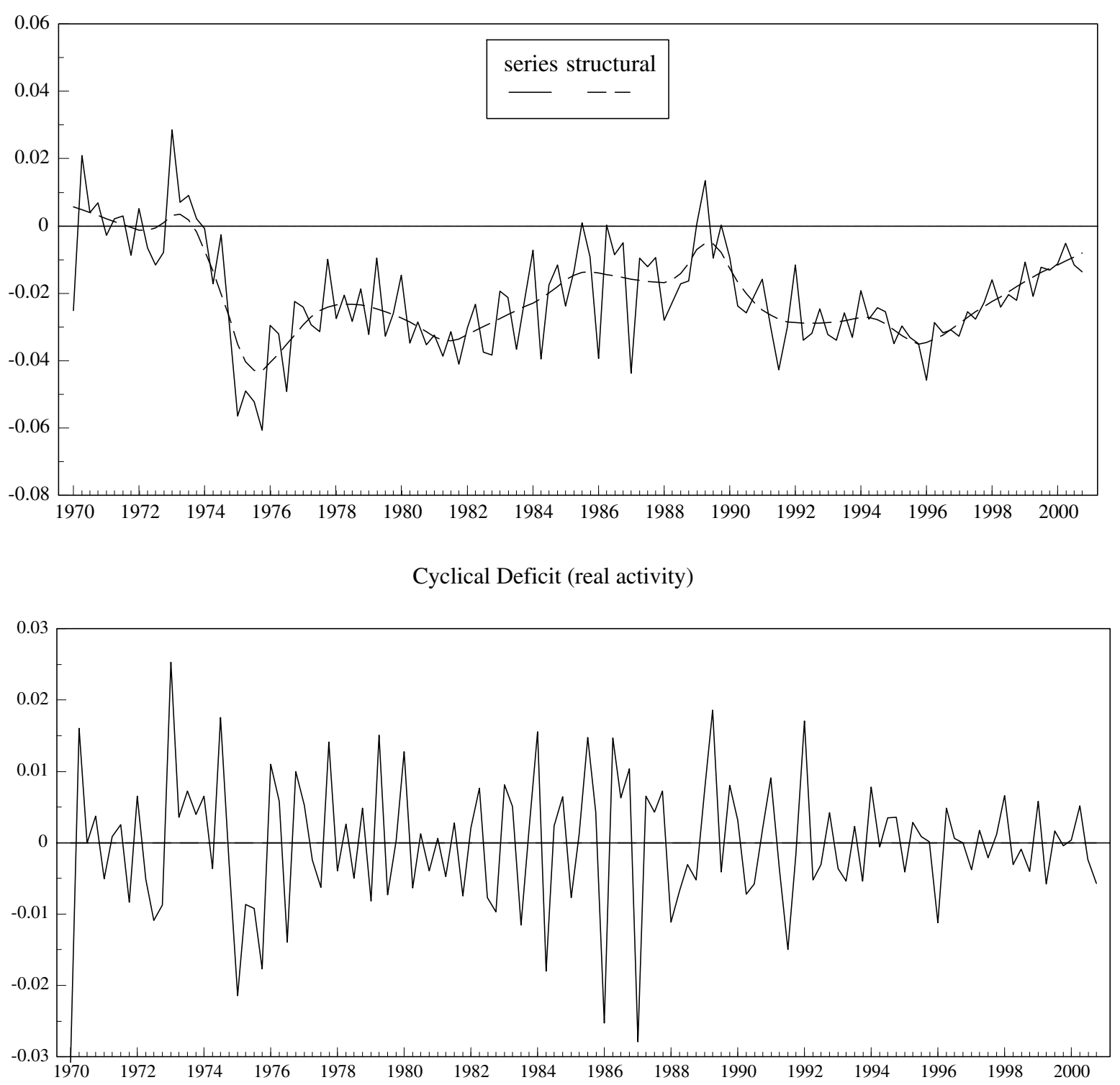
Figure 2: Quarterly Deficit Series Decomposition. Germany. Model 2.

Quarterly Deficit Ratio

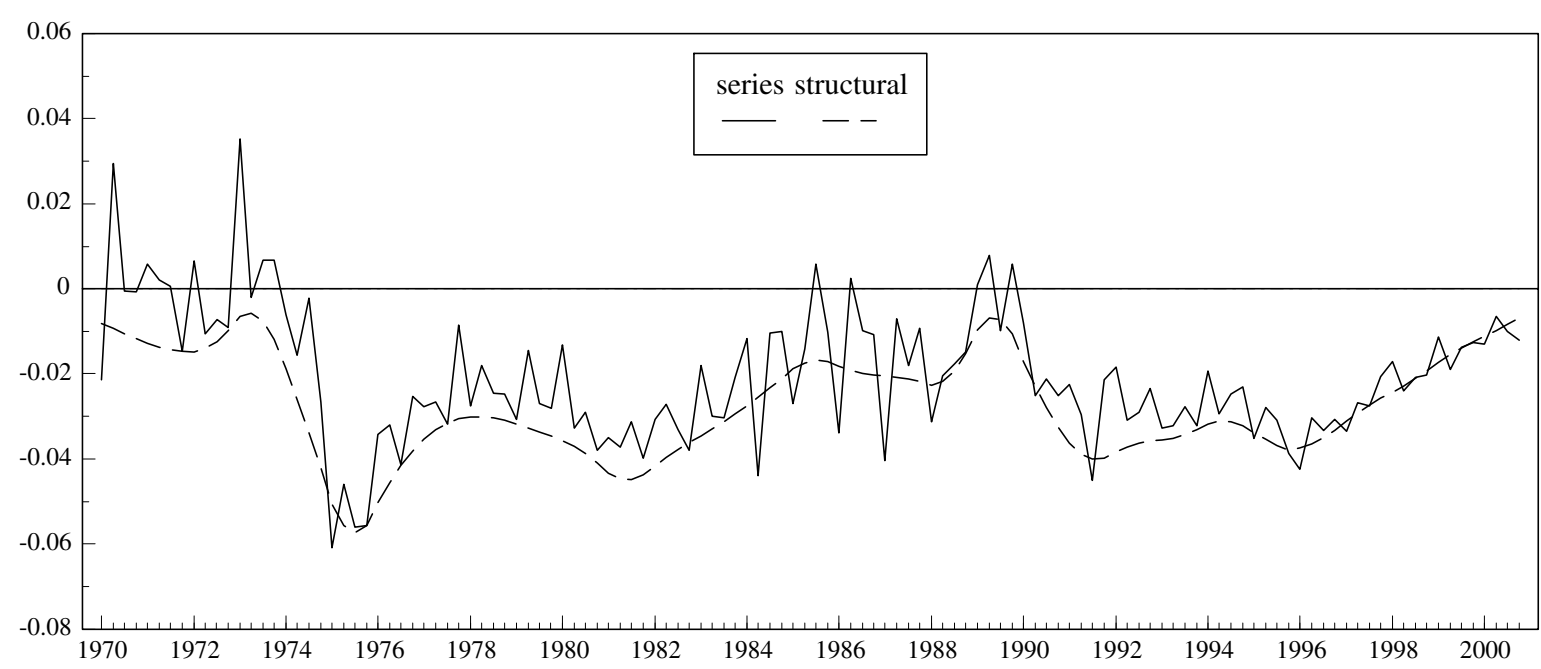

Cyclical Deficit (real activity)
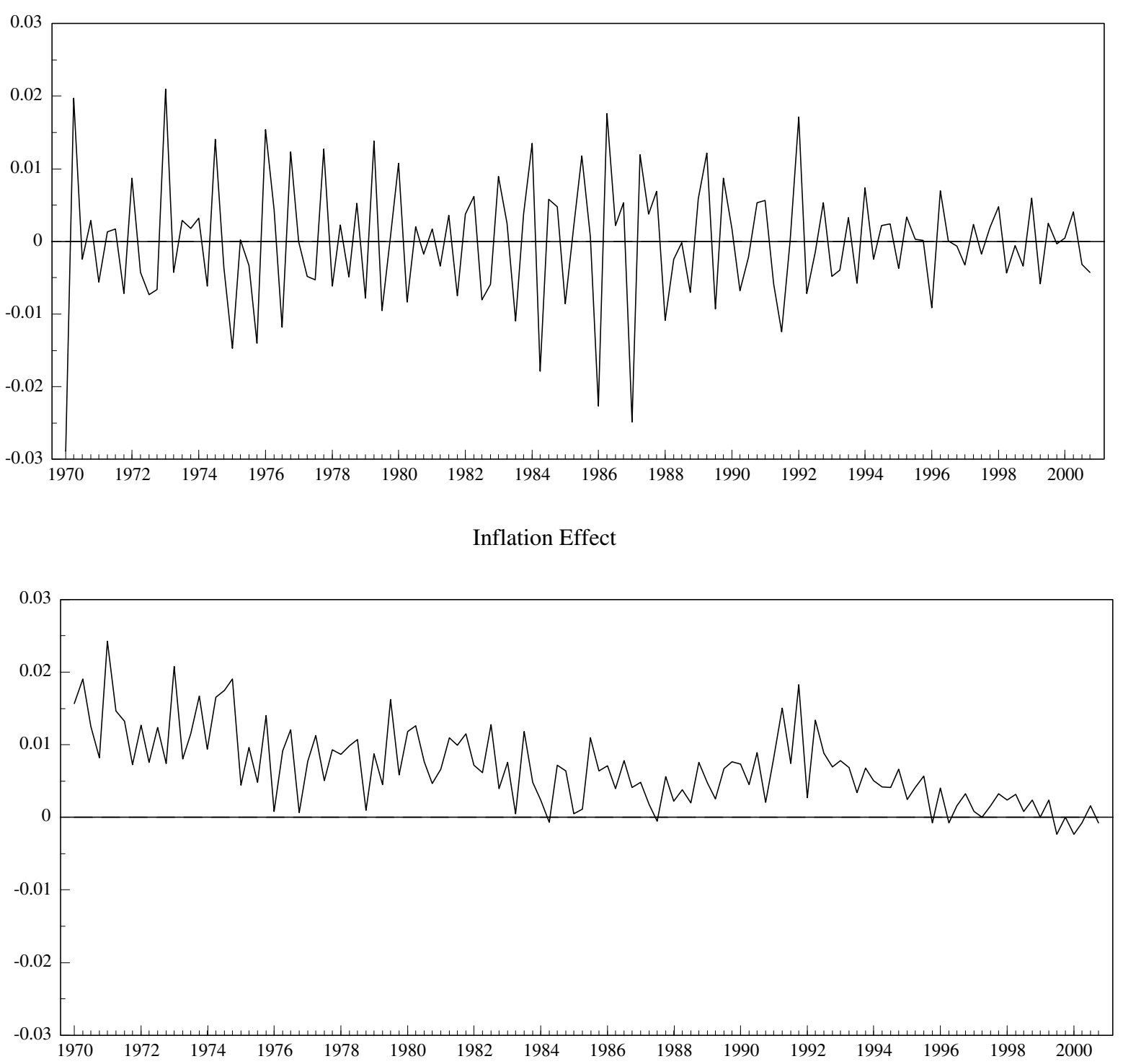
Figure 3: Quarterly Deficit Series Decomposition. Italy. Model 1.

Quarterly Deficit Ratio

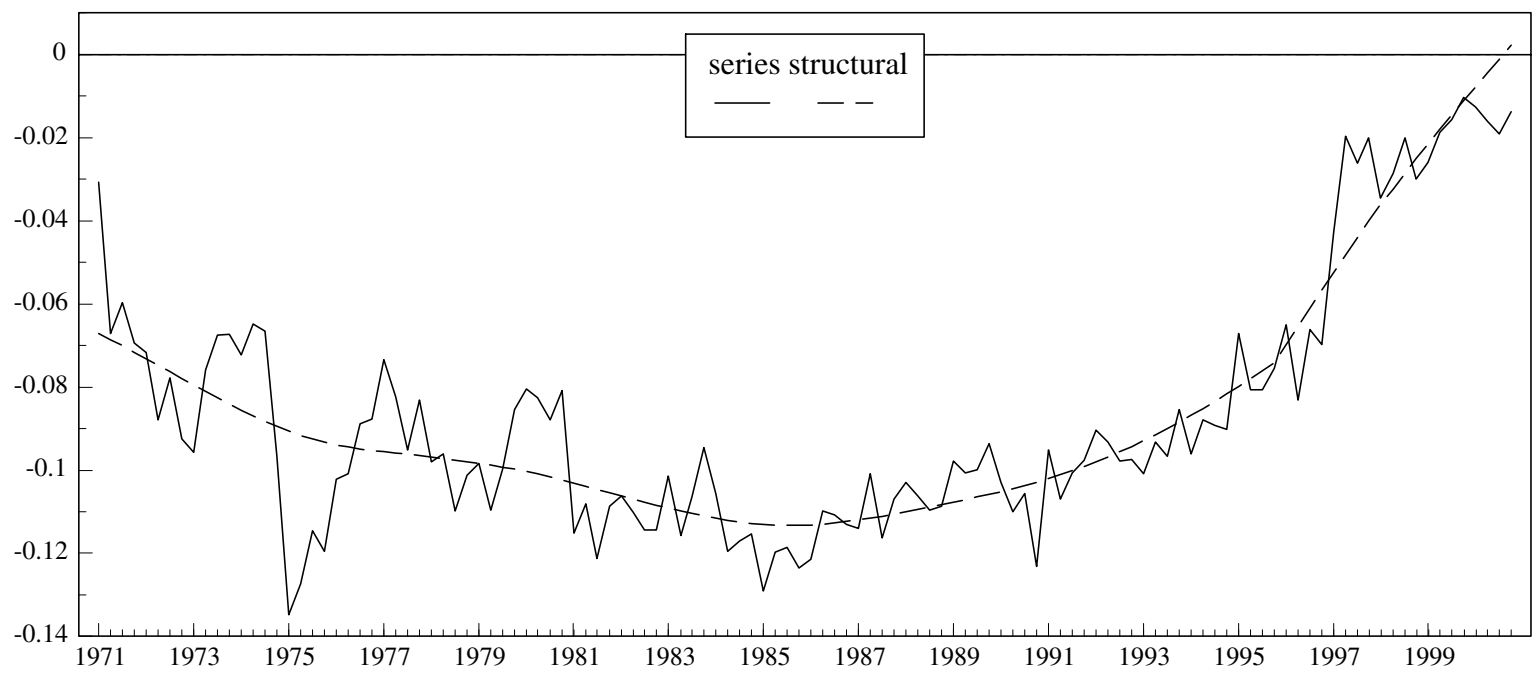

Cyclical Deficit (real activity)

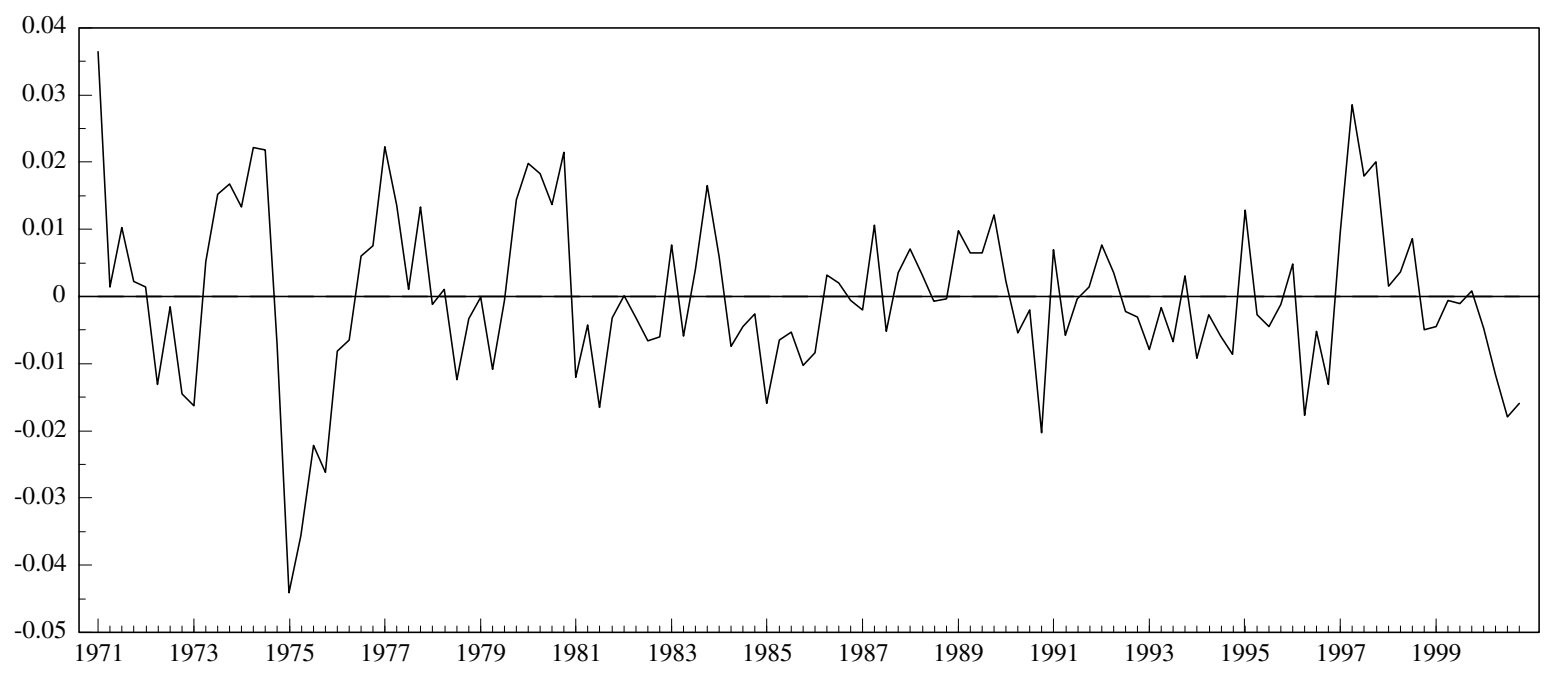


Figure 4: Quarterly Deficit Series Decomposition. Italy, Model 2.

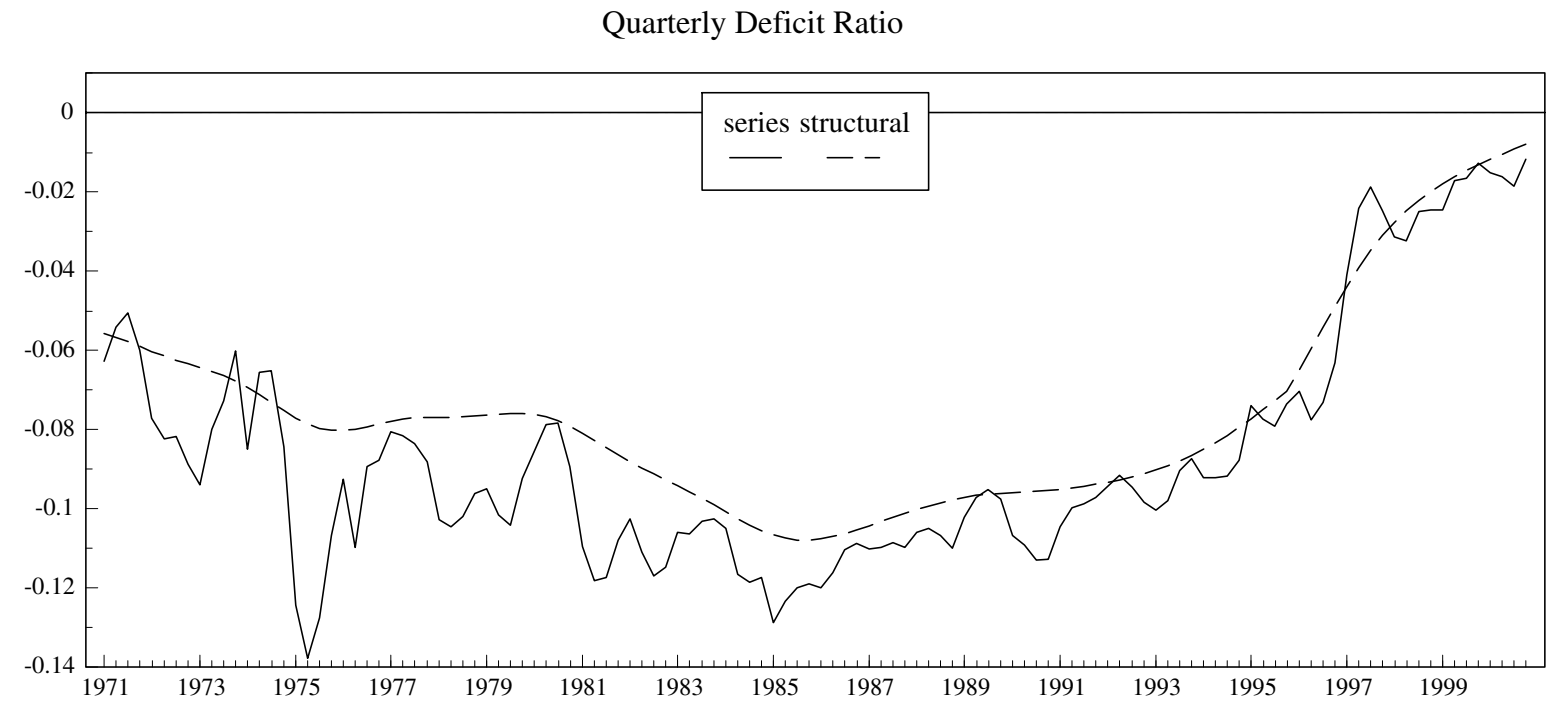

Cyclical Deficit (real activity)

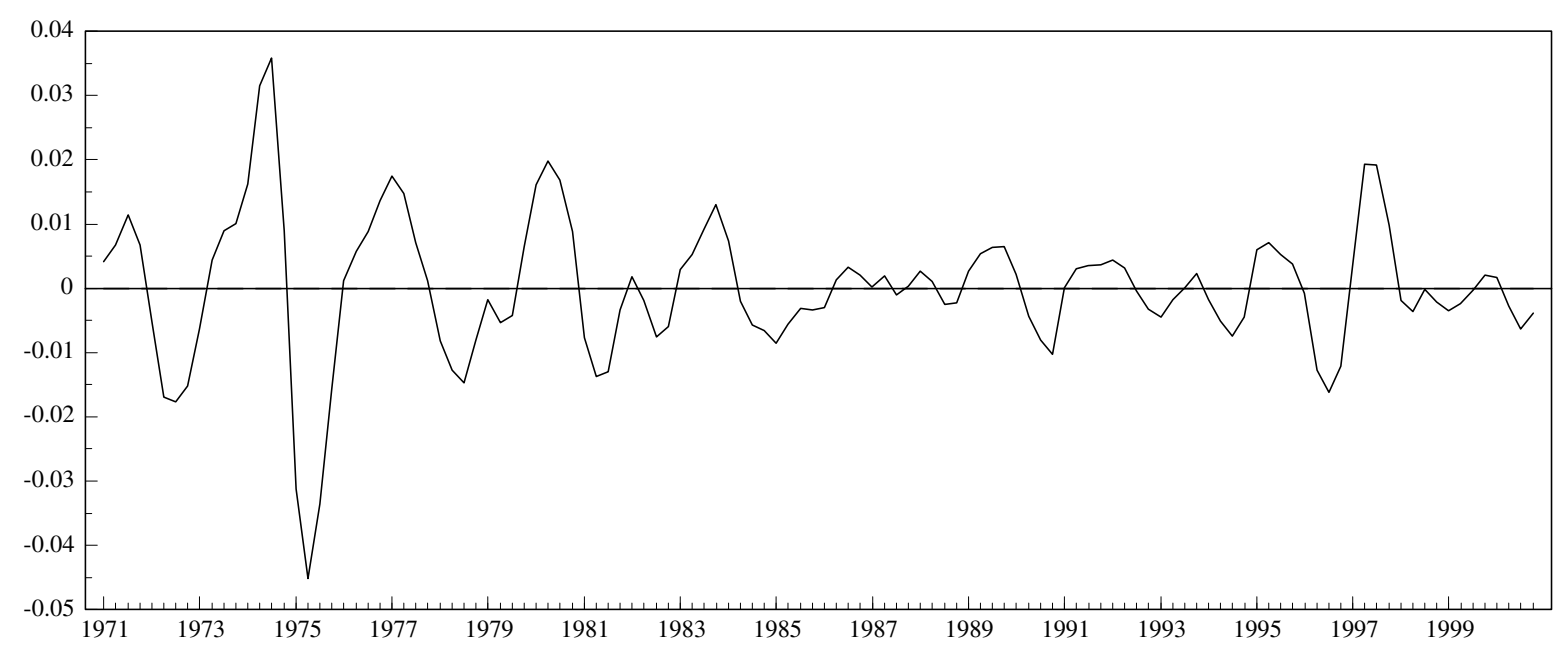

Inflation Effect

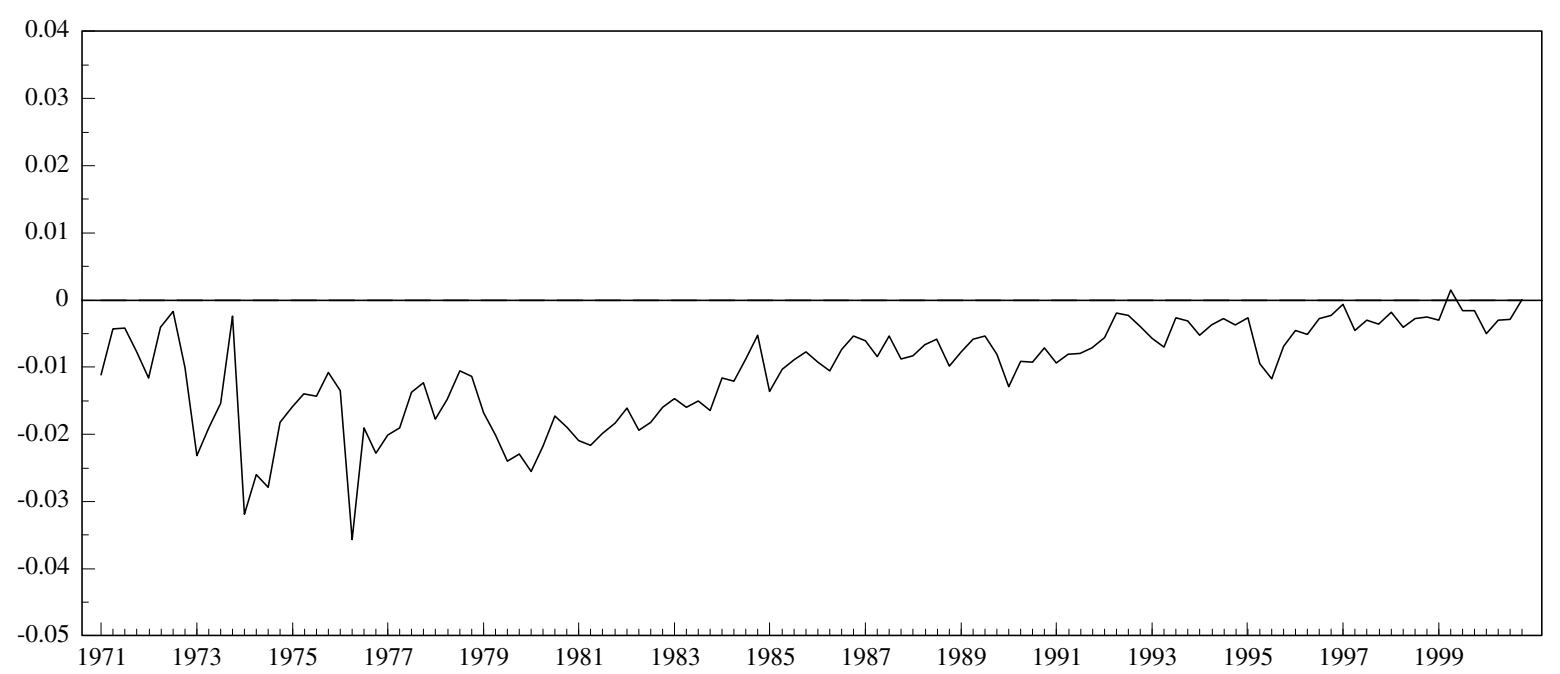


Figure 5: Probability of Structural Deficit going lower than $-2 \%$ for Germany and $-9 \%$ for Italy one quarter ahead. Shaded areas point to when this event ocurred.

Germany Model 1
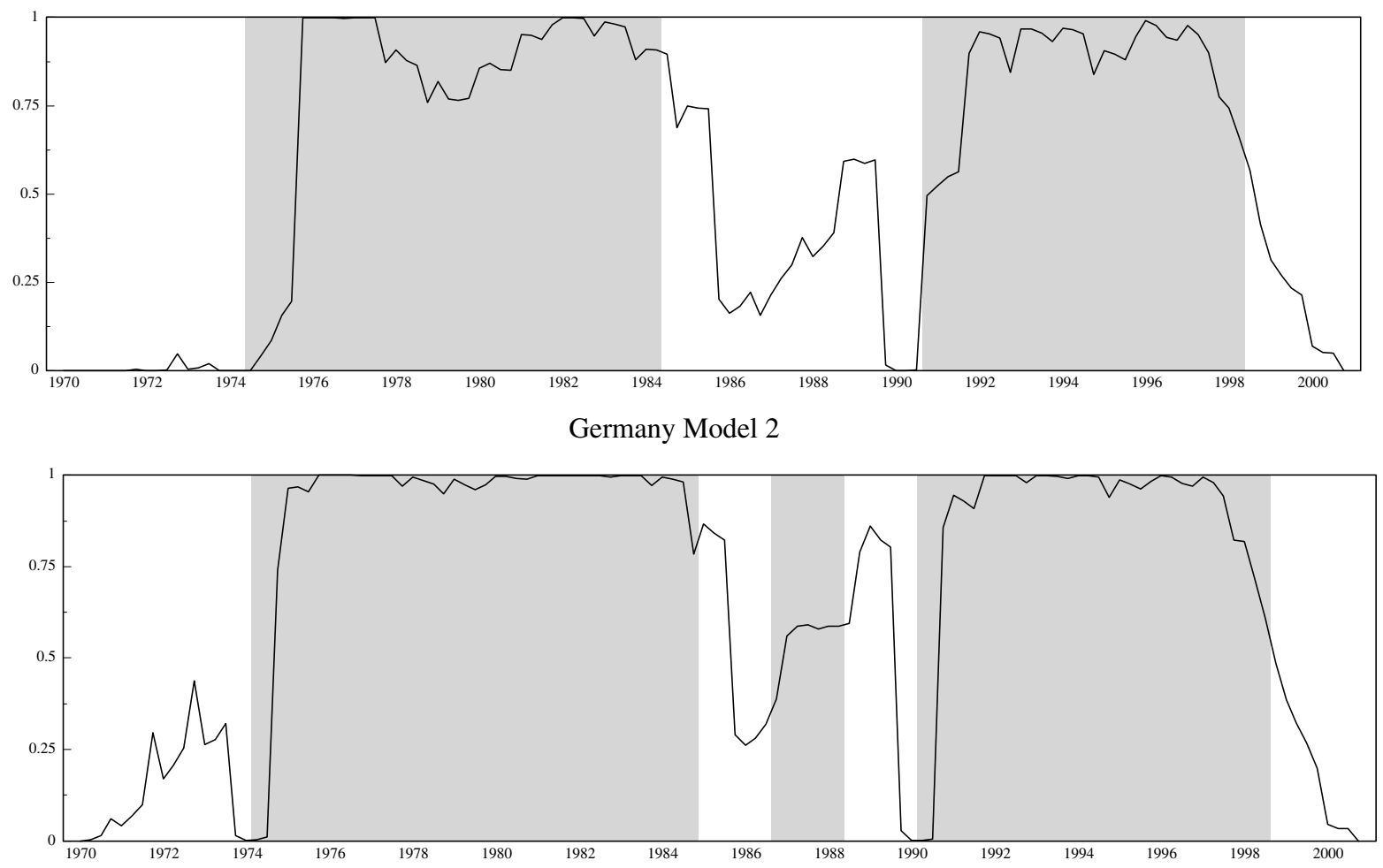

Italy Model 1

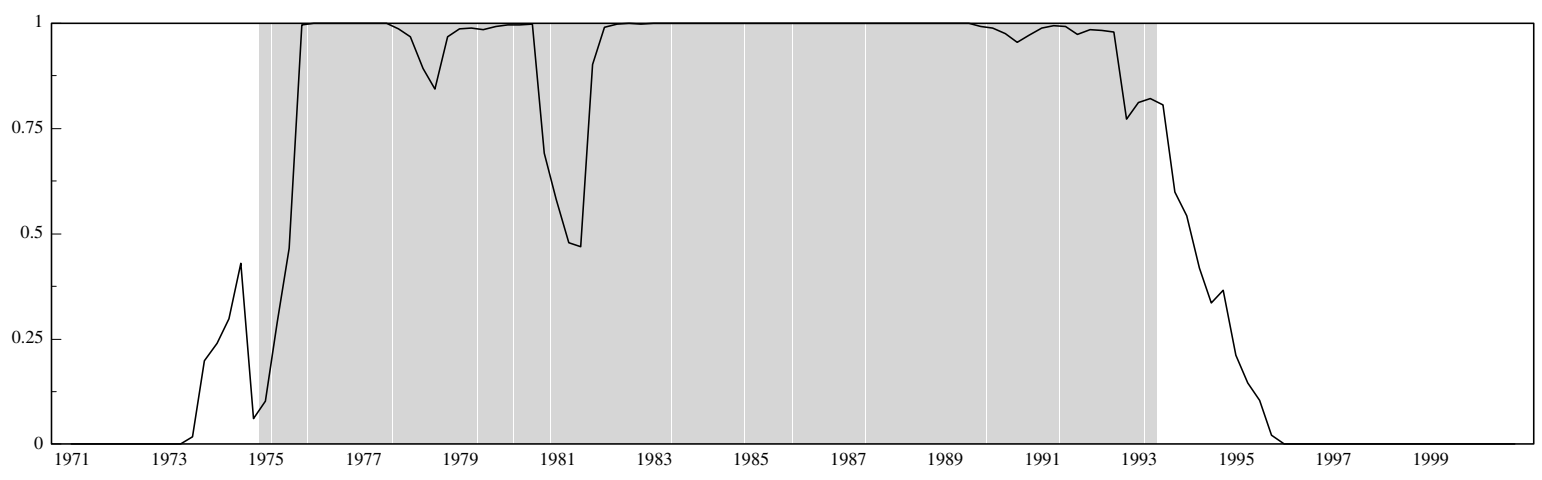

Italy Model 2

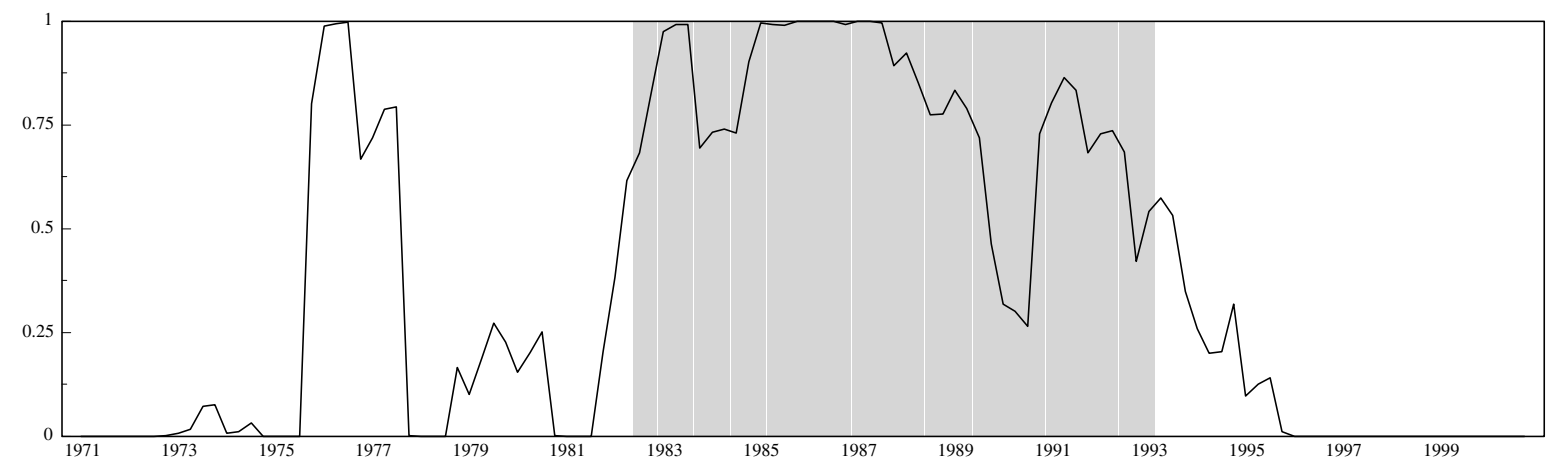




\section{European Central Bank Working Paper Series}

For a complete list of Working Papers published by the ECB, please visit the ECB's website (http://www.ecb.int).

68 "The performance of forecast-based monetary policy rules under model uncertainty" by A. Levin, V. Wieland and J. C.Williams, July 200I.

69 "The ECB monetary policy strategy and the money market" by V. Gaspar, G. Perez-Quiros and J. Sicilia, July $200 \mathrm{I}$.

70 "Central Bank forecasts of liquidity factors: Quality, publication and the control of the overnight rate” by U. Bindseil, July 200 I.

7I “Asset market linkages in crisis periods" by P. Hartmann, S. Straetmans and C. G. de Vries, July 2001.

72 "Bank concentration and retail interest rates" by S. Corvoisier and R. Gropp, July 200 I.

73 "Interbank lending and monetary policy transmission - evidence for Germany" by M. Ehrmann and A. Worms, July $200 \mathrm{I}$.

74 "Interbank market integration under asymmetric information" by X. Freixas and C. Holthausen, August 200I.

75 "Value at risk models in finance" by S. Manganelli and R. F. Engle, August $200 \mathrm{I}$.

76 "Rating agency actions and the pricing of debt and equity of European banks: What can we infer about private sector monitoring of bank soundness?" by R. Gropp and A. J. Richards, August 200I.

77 "Cyclically adjusted budget balances: An alternative approach" by C. Bouthevillain, P. CourThimann, G. van den Dool, P. Hernández de Cos, G. Langenus, M. Mohr, S. Momigliano and M. Tujula, September $200 \mathrm{I}$.

78 "Investment and monetary policy in the euro area" by B. Mojon, F. Smets and P. Vermeulen, September 200I.

79 "Does liquidity matter? Properties of a synthetic divisia monetary aggregate in the euro area" by L. Stracca, October 2001.

80 "The microstructure of the euro money market" by P. Hartmann, M. Manna and A. Manzanares, October 2001.

81 "What can changes in structural factors tell us about unemployment in Europe?" by J. Morgan and A. Mourougane, October 200I.

82 "Economic forecasting: some lessons from recent research" by D. Hendry and M. Clements, October $200 \mathrm{I}$. 
83 "Chi-squared tests of interval and density forecasts, and the Bank of England's fan charts" by K. F. Wallis, November 2001.

84 "Data uncertainty and the role of money as an information variable for monetary policy" by G. Coenen, A. Levin and V. Wieland, November $200 \mathrm{I}$.

85 "Determinants of the euro real effective exchange rate: a BEER/PEER approach" by F. Maeso-Fernandez, C. Osbat and B. Schnatz, November 2001.

86 "Rational expectations and near rational alternatives: how best to form expecations" by M. Beeby, S. G. Hall and S. B. Henry, November 2001.

87 "Credit rationing, output gap and business cycles" by F. Boissay, November 200I.

88 "Why is it so difficult to beat the random walk forecast of exchange rates?" by L. Kilian and M. P. Taylor, November 2001.

89 "Monetary policy and fears of financial instability" by V. Brousseau and C. Detken, November 200I.

90 "Public pensions and growth" by S. Lambrecht, P. Michel and J.-P. Vidal, November $200 \mathrm{I}$.

91 "The monetary transmission mechanism in the euro area: more evidence from VAR analysis" by G. Peersman and F. Smets, December 2001.

92 "A VAR description of the effects of monetary policy in the individual countries of the euro area" by B. Mojon and G. Peersman, December $200 \mathrm{I}$.

93 "The monetary transmission mechanism at the euro-area level: issues and results using structural macroeconomic models" by P. McAdam and J. Morgan, December $200 \mathrm{I}$.

94 "Monetary policy transmission in the euro area: what do aggregate and national structural models tell us?" by P. van Els, A. Locarno, J. Morgan and J.-P. Villetelle, December $200 \mathrm{I}$.

95 "Some stylised facts on the euro area business cycle" by A.-M. Agresti and B. Mojon, December 200I.

96 "The reaction of bank lending to monetary policy measures in Germany" by A. Worms, December $200 \mathrm{l}$.

97 "Asymmetries in bank lending behaviour. Austria during the 1990s" by S. Kaufmann, December 2001.

98 "The credit channel in the Netherlands: evidence from bank balance sheets" by L. De Haan, December 200I.

99 "Is there a bank lending channel of monetary policy in Spain?" by I. Hernando and J. Martínez-Pagés, December 200 I. 
100 "Transmission of monetary policy shocks in Finland: evidence from bank level data on loans" by J. Topi and J. Vilmunen, December $200 \mathrm{I}$.

I0I "Monetary policy and bank lending in France: are there asymmetries?" by C. Loupias, F. Savignac and P. Sevestre, December 200I.

102 "The bank lending channel of monetary policy: identification and estimation using Portuguese micro bank data" by L. Farinha and C. Robalo Marques, December $200 \mathrm{I}$.

103 "Bank-specific characteristics and monetary policy transmission: the case of Italy" by L. Gambacorta, December 200I.

104 "Is there a bank lending channel of monetary policy in Greece? Evidence from bank level data” by S. N. Brissimis, N. C. Kamberoglou and G. T. Simigiannis, December 200I.

105 "Financial systems and the role of banks in monetary policy transmission in the euro area" by M. Ehrmann, L. Gambacorta, J. Martínez-Pagés, P. Sevestre and A. Worms,

December 200I.

106 "Investment, the cost of capital, and monetary policy in the nineties in France: a panel data investigation" by J.-B. Chatelain and A. Tiomo, December $200 \mathrm{I}$.

107 "The interest rate and credit channel in Belgium: an investigation with micro-level firm data" by P. Butzen, C. Fuss and P. Vermeulen, December $200 \mathrm{I}$.

108 "Credit channel and investment behaviour in Austria: a micro-econometric approach" by M. Valderrama, December 200I.

109 "Monetary transmission in Germany: new perspectives on financial constraints and investment spending" by U. von Kalckreuth, December $200 \mathrm{I}$.

I 10 "Does monetary policy have asymmetric effects? A look at the investment decisions of Italian firms" by E. Gaiotti and A. Generale, December 200 I.

I I "Monetary transmission: empirical evidence from Luxembourg firm level data" by P. Lünnemann and T. Mathä, December 200I.

II2 "Firm investment and monetary transmission in the euro area" by J.-B. Chatelain, A. Generale, I. Hernando, U. von Kalckreuth and P. Vermeulen, December 200I.

II 3 "Financial frictions and the monetary transmission mechanism: theory, evidence and policy implications" by C. Bean, J. Larsen and K. Nikolov, January 2002.

II4 "Monetary transmission in the euro area: where do we stand?" by I. Angeloni, A. Kashyap, B. Mojon, D. Terlizzese, January 2002.

II 5 "Monetary policy rules, macroeconomic stability and inflation: a view from the trenches" by A. Orphanides, December 2001 .

116 "Rent indices for housing in West Germany 1985 to 1998" by J. Hoffmann and C. Kurz., January 2002. 
117 "Hedonic house prices without characteristics: the case of new multiunit housing" by O. Bover and P. Velilla, January 2002.

118 "Durable goods, price indexes and quality change: an application to automobile prices in Italy, 1988-1998” by G. M. Tomat, January 2002.

119 "Monetary policy and the stock market in the euro area" by N. Cassola and C. Morana, January 2002.

120 "Learning stability in economics with heterogenous agents" by S. Honkapohja and K. Mitra, January 2002.

12I "Natural rate doubts" by A. Beyer and R. E. A. Farmer, February 2002.

122 "New technologies and productivity growth in the euro area" by F. Vijselaar and R. Albers, February 2002.

123 "Analysing and combining multiple credit assessments of financial institutions" by E. Tabakis and A. Vinci, February 2002.

124 "Monetary policy, expectations and commitment" by G. W. Evans and S. Honkapohja, February 2002.

125 "Duration, volume and volatility impact of trades" by S. Manganelli, February 2002.

126 "Optimal contracts in a dynamic costly state verification model" by C. Monnet and E. Quintin, February 2002.

127 "Performance of monetary policy with internal central bank forecasting" by S. Honkapohja and K. Mitra, February 2002.

128 "Openness, imperfect exchange rate pass-through and monetary policy" by F. Smets and R. Wouters, February 2002.

129 "Non-standard central bank loss functions, skewed risks, and certainty equivalence" by A. al-Nowaihi and L. Stracca, March 2002.

I30 "Harmonized indexes of consumer prices: their conceptual foundations" by E. Diewert, March 2002.

I3I "Measurement bias in the HICP: what do we know, and what do we need to know?" by M. A. Wynne and D. Rodríguez-Palenzuela, March 2002.

132 "Inflation dynamics and dual inflation in accession countries: a "new Keynesian" perspective” by O. Arratibel, D. Rodríguez-Palenzuela and C. Thimann, March 2002.

133 "Can confidence indicators be useful to predict short term real GDP growth?" by A. Mourougane and M. Roma, March 2002. 
134 "The cost of private transportation in the Netherlands, 1992-1999" by B. Bode and J. Van Dalen, March 2002.

135 "The optimal mix of taxes on money, consumption and income" by F. De Fiore and P. Teles, April 2002.

I36 "Retail bank interest rate pass-through: the new evidence at the euro area level" by G. de Bondt, April 2002.

137 "Equilibrium bidding in the eurosystem's open market operations" by U. Bindseil, April 2002.

138 "New" views on the optimum currency area theory: what is EMU telling us?" by F. P. Mongelli, April 2002.

139 "On currency crises and contagion" by M. Fratzscher, April 2002.

140 "Price setting and the steady-state effects of inflation" by M. Casares, May 2002.

14I "Asset prices and fiscal balances" by F. Eschenbach and L. Schuknecht, May 2002.

142 "Modelling the daily banknotes in circulation in the context of the liquidity management of the European Central Bank", by A. Cabrero, G. Camba-Mendez, A. Hirsch and F. Nieto, May 2002.

I43 “A non-parametric method for valuing new goods", by I. Crawford, May 2002.

144 "A failure in the measurement of inflation: results from a hedonic and matched experiment using scanner data", by M. Silver and S. Heravi, May 2002.

145 "Towards a new early warning system of financial crises", by M. Fratzscher and M. Bussiere, May 2002.

146 “Competition and statility - whats special about banking?", by E. Carletti and P. Hartmann, May 2002.

147 "Time-to-build approach in a sticky price, stricky wage optimizing monetary model, by M. Casares, May 2002.

148 "The functional form of yield curves" by V. Brousseau, May 2002.

149 "The Spanish block of the ESCB-multi-country model" by A. Estrada and A. Willman, May 2002.

150 "Equity and bond market signals as leading indicators of bank fragility" by R. Gropp, J. Vesala and G. Vulpes, June 2002.

I5I "G-7 Inflation forecasts" by F. Canova, June 2002.

152 "Short-term monitoring of fiscal policy discipline" by G. Camba-Mendez and A. Lamo, June 2002. 